\title{
Mori-Tanaka-based statistical methodology to compute the effective Young modulus of polymer matrix nano-composites considering the experimental quantification of nanotubes dispersion and alignment degree
}

\author{
Iván David Patiño ${ }^{a}$ and Cesar Augusto Isaza ${ }^{b *}$
}

anstitución Universitaria Pascual Bravo, Facultad de Ingeniería, Grupo GIIAN, A. A. 6564, campus Robledo, Medellín, Colombia ${ }^{b}$ Institución Universitaria Pascual Bravo, Facultad de Ingeniería, Grupo GIIEN, A. A. 6564, campus Robledo, Medellín, Colombia

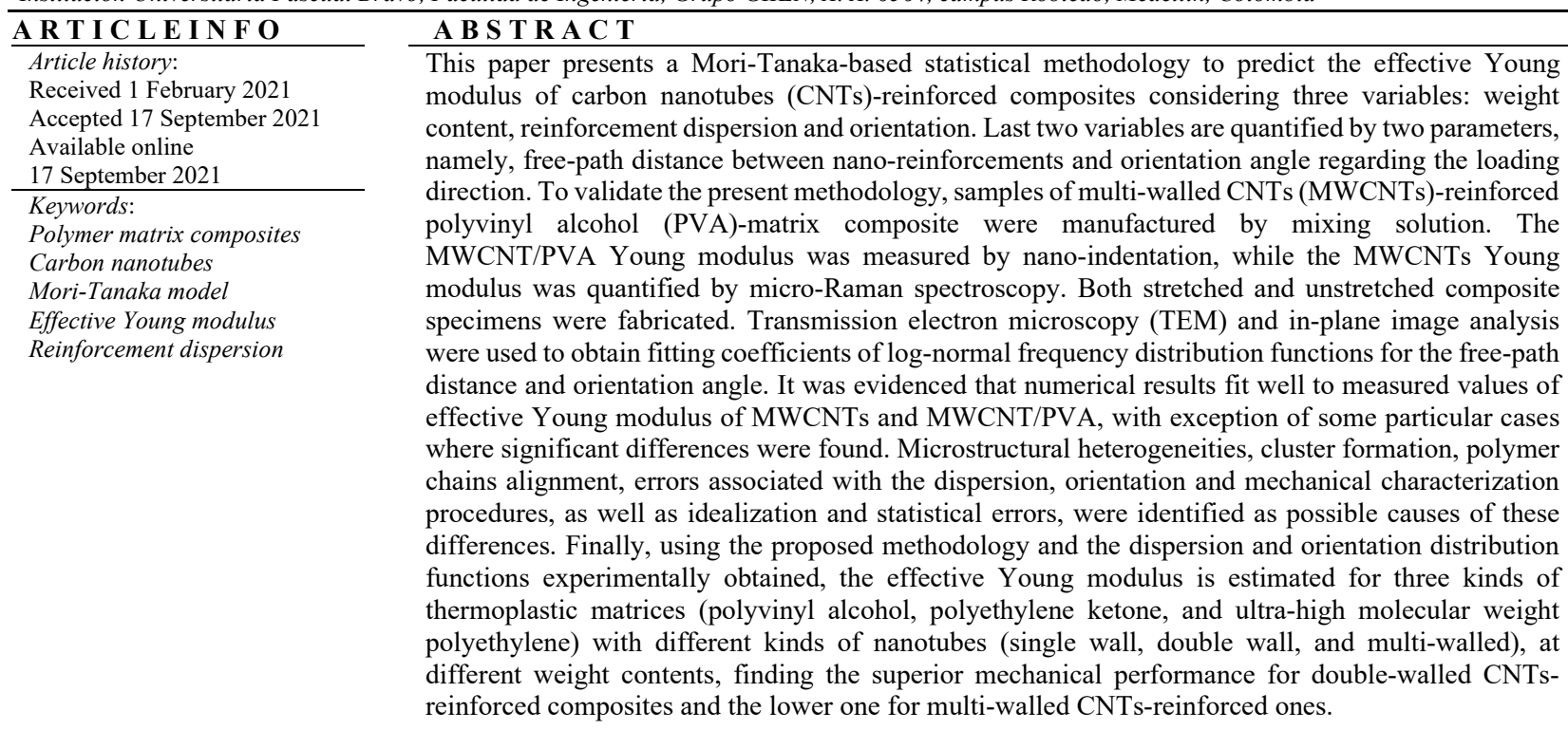

\section{Introduction}

Since their discovery by Ijiima (Iijima, 1991) in the 1990s, the carbon nanotubes (CNTs) began to be the cornerstone in several scientific branches, from physics to chemistry, going through medicine and biology. In materials science, technology and applied engineering, a large number of studies has been conducted on CNTs, due to their extraordinary mechanical, thermal and physical properties (Coleman et al. 2006; Hone et al., 2002; Xie et al. 2000). CNTs have been studied as potential reinforcements for composites for improving the mechanical properties; these studies have increased demand from automotive and aerospace sectors to develop new advanced materials, which contribute to weight savings, improve energy efficiency, withstand harsh structural loadings and enhance tribological performances. However, dispersion and alignment of CNTs in

* Corresponding author. Tel.: +57-3017095254

E-mail addresses: c.isaza2059@pascualbravo.edu.co (C. A. Isaza) 
the matrix has been difficult to reach due to their tendency to form clusters because of Van der Waals forces on the surface. Well dispersed CNTs into the matrix are crucial to optimize the general composite performance. In general, CNTs clusters have lower strength, higher porosity and acts as discontinuities, which decrease the mechanical, electrical and thermal properties of the composite; additionally, the well dispersed CNTs into the matrix prevents slippage between CNTs and CNTs/Matrix (Desai \& Haque, 2005). There are several techniques to improve the dispersion of CNTs in polymer matrices, such as mechanical dispersion techniques: ultrasonication (Chen et al., 2018; Isaza et al. 2018), high shear stress (Noor et al., 2018), calendering process (Vázquez-Moreno et al., 2019), ball-milling (Enqvist et al. 2016) stirring (Guo et al. 2018) and extrusion (Verma et al., 2015). In agreement with conventional fiber composites, in polymer/CNTs composites, both strength and stiffness properties, as well as functional properties such as electrical, magnetic and optical ones, are directly linked to the alignment of CNTs in the matrix. Different methods for aligning CNTs in polymer matrices have been used: ex situ alignment (Feng et al., 2003), force field-induced (Gao et al. 2018), magnetic field-induced (Shi et al., 2018), electro-spinninginduced (Huang et al. 2003) and mechanical stretching (Isaza et al., 2018).

To predict the mechanical properties of composites materials, several studies have been carried out and some important theories for the effective strengths and elastic moduli of polymer matrix composites (PMCs) have been developed. Most of these works are focused on composite materials comprising isotropic or transversely isotropic constituents, and some of them have been adapted for CNTs reinforced composites. One of the first theories for calculating the mechanical properties of composite systems was developed for elastomers and is based on Einstein's equation for the viscosity of a suspension of rigid spherical inclusions (Ahmed \& Jones, 1990), as shown in Eq. (1).

$$
\mathrm{G}_{\mathrm{c}}=\mathrm{G}_{\mathrm{m}}\left(1+2,5 \mathrm{~V}_{r}\right)
$$

where $\mathrm{G}$ is the shear modulus and $r, m$ and $c$ refer to reinforcement, matrix and composite phases, respectively, whereas $V_{r}$ is the volume fraction of the particulate inclusions. Later, Mooney (1951) and Brodnyan (1959) modified Einstein's equation considering a crowding factor (volume occupied by the filler/true volume of the filler) and the aspect ratio of the particle. The random distribution of the constituent phases in a filled system demands a statistical approach, implying the knowledge of the distribution of the individual phases. The average behavior of the composite is defined for a Representative Elementary Volume (RUC) using the Rule of Mixture (ROM), as shown in Eqs. (2) and (3), where modulus of the composite for both parallel and orthogonal arrangement are represented, respectively. Note that in these formulae, only three parameters are involved, i.e., modulus of the fiber and matrix, and the fiber volume fraction.

$$
\begin{aligned}
& E_{c}=E_{r} V_{r}+E_{m} V_{m}, \text { for the case of parallel arrangement } \\
& E_{c}=\frac{E_{p} E_{m}}{E_{p} V_{m}+E_{m} V_{p}}, \text { for the case of orthogonal arrangement }
\end{aligned}
$$

According to (Armbrister et al. 2015; Ebrahimi \& Dabbagh, 2019; Hu et al., 2010; Kundalwal, 2018), micromechanical models can be grouped into the following families: strength of material approaches, Halpin-Tsai equations, multi-phase mechanics of materials (MOM) approaches, multiphase Mori-Tanaka (MT) models, composite cylindrical assemblage models, Voigt-Reuss models, modified mixture rules, Cox model, effective medium approaches and methods of cells. The application of each model to CNTs reinforced composites strongly depends on the dispersion degree, CNT alignment, CNT weight content and aspect ratio of the carbon nanotubes. For randomly oriented reinforcements, some suitable models are: Halpin-Tsai, Voigth-Reus, Cox, and Christensen-Waals. Voigh-Reus (Reuss, 1929) and Halpin-Tsai (Halpin, 1969; Halpin \& Kardos, 1976) developed semi-empirical models for short fiber-reinforced composite laminae, where the principal difference between both models lies in the consideration of the geometrical parameters of the reinforcement. Halpin-Tsai considers the aspect ratio of the fiber, while Voigh-Reus does not deem any geometrical parameter. In the Halpin-Tsai model, the longitudinal and transverse moduli of aligned fibers are given by Eq. (4) to Eq. (7), and then (8) can be used to estimate the effective Young modulus of the randomly oriented fiber composite. The main assumptions of this model are perfect fibermatrix bonding, good dispersion and high aspect ratio; when opposite phenomena takes place in the composite, the model accuracy can be significantly affected (Sharma \& Shukla, 2014). In some works (Coleman et al., 2006; Rafiee et al., 2009; Yeh et al., 2006), Halpin-Tsai model has been found to be acceptable for low CNTs volume content in polymer matrix composites. According to De Villoria and Miravete (2007), this model generates reliable results for composite laminae, but not for three dimensional solids.

$$
\begin{aligned}
& E_{L}=\frac{1+2\left(\frac{l}{d}\right) V_{f} \eta_{L}}{V_{m} \eta_{L}} E_{m} \\
& E_{T}=\frac{1+2 V_{f} \eta_{T}}{V_{m} \eta_{T}} E_{m}
\end{aligned}
$$

where $\eta_{L}$ and $\eta_{\mathrm{T}}$ take the following form: 


$$
\begin{aligned}
& \eta_{L}=\frac{E_{f}-E_{m}}{E_{f}+2\left(\frac{l}{d}\right) E_{m}} \\
& \eta_{T}=\frac{E_{f}-E_{m}}{E_{f}+2 E_{m}} \\
& E_{H T}=\frac{3}{8} E_{L}+\frac{5}{8} E_{T}
\end{aligned}
$$

The modified mixture law (MML) can be applied to three dimensional, randomly aligned, short fiber composites using the Piggot formulation (Stecenko \& Piggott, 1997), which does not consider any geometrical parameter of the reinforcement. According to this formulation, composite Young's modulus $\mathrm{E}_{\mathrm{c}}$ can be predicted using eq. (9).

$$
E_{c}=\eta E_{f} V_{f}+E_{m}\left(1-V_{f}\right)
$$

where $\eta$ is a load transfer efficiency factor, which is considered as 0.20 for nano-composites, whereas for macro and microcomposites, a value of 1 is used, which comes from the Hooke's law on a fiber cross section. The effect of the aspect ratio of fibers is incorporated in the MML model by the Cox law (Cox, 1952), which is a "shear lag" model where short fibers into a metal matrix are perfectly anchored, i.e., the shear stresses are completely transmitted between reinforcement and matrix; the maximum tensile stress is reached at the fiber longitudinal center, while the shear stress reaches its maximum towards the fiber ends; this occurs because the fibers are aligned in the direction of the applied load. In the Cox law, the load transfer efficiency factor, $\eta$, is taken as a function of the fiber geometry. As a "shear lag" model, $\eta$ is calculated as shown in Eq. (10).

$$
\eta=\left[1-\frac{\tan \mathrm{h}\left(\beta \cdot \mathrm{l}_{f} / 2\right)}{\beta \cdot \mathrm{l}_{f} / 2}\right]
$$

where $l_{f}$ is the fiber length and $\beta$ is the shear lag parameter as given by Eq. (11).

$$
\beta=\sqrt{\frac{4 G_{m}}{E_{f} r_{f}^{2} \ln \left(\frac{K_{R}}{V_{f}}\right)}}
$$

With $G_{m}$ as the shear modulus of the matrix, $K_{R}$ as a constant depending on the fiber packing arrangements (Hu et al., 2010), and $r_{f}$ as the fiber radius. In CNT reinforced composites, Cox model has found to be suitable for metal matrix composites when dispersion degree and CNT weight fractions are high (Choi et al. 2009), but inaccurate in CNT reinforced epoxy composites (De Villoria \& Miravete, 2007). A modification of the Cox model (Gao \& Li, 2005) using a multi-scale approach was developed for CNTs-reinforced polymer composites, obtaining satisfactory results regarding experimental and numerical data. On the contrary to Voigth-Reus and Halpin-Tsai, Cox model is suitable for 3D solid composites. A method to obtain the effective Young modulus and Poisson ratio of two dimensional randomly-oriented fiber composites was described by Christensen-Waals (Christensen \& Waals, 1972), which is based on the Hashin and Shtrikman model (Hashin, 1983; Hashin \& Shtrikman, 1963). This method can be applicable for three phase composites, containing resin, fillers, and fibers. This assumes macroscopic isotropy and quasi-homogeneity of the composite where the filler shape is not a limiting factor, and estimates the upper and lower bounds of the effective bulk $(K)$ and shear modulus $(G)$ of the equivalent resin-filler phase based on variational principles of elasticity, as given by Eq. (12) to Eq. (15):

$$
\begin{aligned}
& K_{\text {upper }}=E_{f}+\left(V_{m}\right)\left[\frac{1}{E_{m}-E_{f}}+\frac{3 V_{f}}{3 E_{f}+4 G_{f}}\right]^{-1} \\
& K_{\text {lower }}=E_{m}+\left(V_{f}\right)\left[\frac{1}{E_{f}-E_{m}}+\frac{3 V_{m}}{3 E_{m}+4 G_{m}}\right]^{-1} \\
& G_{\text {upper }}=G_{f}+\left(V_{m}\right)\left[\frac{1}{G_{m}-G_{f}}+\frac{6 V_{f}\left(E_{f}+2 G_{f}\right)}{5 G_{f}\left(3 E_{f}+4 G_{f}\right)}\right]^{-1} \\
& G_{\text {lower }}=G_{m}+\left(V_{f}\right)\left[\frac{1}{G_{f}-G_{m}}+\frac{6 V_{m}\left(E_{m}+2 G_{m}\right)}{5 G_{f}\left(3 E_{m}+4 G_{m}\right)}\right]^{-1}
\end{aligned}
$$

In the Christensen-Waals method, once the effective bulk and shear modulus for the equivalent matrix phase (filler/matrix) has been obtained as a weighted average of the lower and upper bounds, the elastic constants of the fiber/equivalent matrix mixture can be found using the formulae of Hill (Hill, 1965) and Hashin (1966). Since the effective Young modulus of the 
composite, $E(\theta)$, can be computed in terms of these elastic constants and the fiber orientation, $\theta$, the average Young modulus for a randomly oriented fiber composite, $E_{c}$, is equivalent to integrate $E(\theta)$ as shown in Eq. (16):

$$
E_{c}=\frac{1}{\pi} \int_{0}^{\pi} E(\theta) \cdot d \theta
$$

One of the critical issues to apply this method to CNTs reinforced composites is the computation of the weighted-average bulk and shear modulus on the basis of the lower and upper bounds given in Eq. (12) to Eq. (15), since CNTs reinforcements could be highly anisotropic and these equations are though for isotropic materials. On the other hand, for fiber-oriented composites, some common models are: Halpin-Tsai, two and three phase MOM, two and three phase MT, Composite Cylindrical Assemblage and Methods of Cells. Halpin-Tsai equation for aligned short fibers is given as (Mallick, 2007; Tucker \& Liang, 1999):

$$
\frac{P}{P^{m}}=\frac{1+\xi \eta V_{f}}{1-\eta V_{f}}
$$

where $P$ stands for the composite property (Young modulus, shear modulus, Poisson's modulus), $f$ and $m$ refers to fibers and matrix, respectively, and the constant $\eta$ is computed as follows:

$$
\eta=\frac{\left(P^{f} / P^{m}\right)-1}{\left(P^{f} / P^{m}\right)+\xi}
$$

where $\xi$ is a shape parameter dependent on the reinforcement geometry, packing configuration and particular elastic property being considered. Halpin-Tsai model is a simple model since it is based on the following assumptions: perfect fiber-matrix bonding, perfect fiber alignment, and uniform fiber shape and sizes. A modified Halpin-Tsai equation was proposed (Yeh et al., 2006) to investigate the effect of the multi-walled carbon nanotubes content (MWCNTs) of phenolic-matrix composites on the Young modulus and tensile strength, achieving similar analytical results to the experimental ones. In Coleman et al., (2006), it was found that Halpin-Tsai model can be appropriate for low CNTs concentrations because it does not account for the strengthening effect caused by clustering. Moreover, the effect of the presence of pores on the mechanical behavior of functionally graded graphene platelets reinforced (FG-GPLR) nano-composite cylinders was studied in (Barati \& Zenkour, 2019) using the Halpin-Tsai model combined with a saturated porous model. Arani et al. (2016) studied the influence of CNTs concentration and aspect ratio on the vibration of carbon nanotubes/fiber/polymer composite micro-plates, where the Halpin Tsai model was used to evaluate the mechanical properties of the two-phase CNT/epoxy composite considered in such research.

Mechanics of materials models (MOM) can be classified as two-phase or three phase models. In the first case, only fibers and matrix are considered, whereas in the second one, an additional phase corresponding to the fiber-matrix interphase is taken into account. In the MOM approach, isofield conditions and rule of mixtures (ROM) are applied to obtain expressions for the stress and strain vector of the composite material in terms of the stress and strain vector of the constituent phases (Hyer \& White, 2009; Smith \& Auld, 1991); afterwards, the effective elastic coefficient matrix can be achieved. Shingare \& Kundalwal (2019) used MOM in conjunction with Kirchhoff's plate theory, Navier's solution and extended linear piezoelectricity theory to study the electromechanical behavior of graphene reinforced nano-composite (GRNC) plates with flexoelectric effect. In a similar fashion, a MOM model was developed (Shingare et al., 2020) to predict the effective properties of GRNC plates subjected to electromechanical loading, obtaining similar results regarding Finite Element Method (FEM) simulations when load is applied along the longitudinal direction. The three-phase MOM was used by Rathi \& Kundalwal, (2020) to predict the effective elastic properties of MWCNT reinforced polymer matrix composites with a fiber-matrix interphase enhanced with zirconium dioxide, evaluating the improvement of the fracture strength and toughness.

On the other hand, Composites Cylindrical Assemblage (CCA) model initially proposed by Hashin et al. (Hashin \& Rosen, 1964) allows calculating the effective elastic moduli (axial Young modulus, longitudinal Poisson ratio, longitudinal shear modulus, bulk modulus and transverse shear modulus) of composites reinforced with aligned, hollow fibers, for a determined RUC arrangement. This model was implemented by Kumar \& Srinivas, (2018) to study the effect of interlayers, chirality, interspacing, fiber volume fraction, interphase properties and temperature conditions on the elastic modulus of MWCNT reinforced polymer matrix composites, reaching similar results to the ones obtained by a RUC finite element model. Furthermore, CCA model has been used together with Mori-Tanaka (MT) model to study the effects of the properties of the interphase layer between nanotubes and polymer resin on the elastic properties of carbon nano-composites (Seidel \& Lagoudas, 2006), finding similar results with FEM simulations.

One of the most widely employed methods for modelling the mechanical properties of CNT fiber aligned composites is Mori-Tanaka (MT), which allows considering the interaction between neighboring reinforcements (Mori \& Tanaka, 1973). 
This model in turns is based on the principles of Eshelby's inclusion model, where the strain and stress field in the matrix and elliptical inclusions (reinforcements) are predicted. Similarly to the MOM model, MT can be applied for two-phases and three-phases composites. MT model was first applied for predicting the elastic properties of fiber reinforced composites (Tandon \& Weng, 1984; Taya \& Chou, 1981; Weng, 1984), and then, Hui and Shia (Hui \& Shia, 1998) adjusted the MT model for predicting the overall moduli of aligned fiber reinforced composites with emphasis on fiber-like and flake-like reinforcements, as shown in Eqs. (19) to (23).

$$
\begin{aligned}
& E_{L}=E_{m}\left[1-\frac{V_{f}}{\xi}\right]^{-1} \\
& E_{T}=E_{m}\left[1-\frac{V_{f}}{4}\left(\frac{1}{\xi}+\frac{3}{\xi+\Lambda}\right]^{-1}\right. \\
& \xi=V_{f}+\frac{E_{m}}{E_{f}-E_{m}}+3\left(V_{m}\right)\left[\frac{(1-g) \alpha_{f}^{2}-g / 2}{\alpha_{f}^{2}-1}\right] \\
& \Lambda=V_{m}\left[\frac{3\left(\alpha_{f}^{2}+0.25\right) g-2 \alpha_{f}^{2}}{\alpha_{f}^{2}-1}\right] \\
& g=\left\{\begin{array}{l}
\frac{\alpha_{f}}{\left(1-\alpha_{f}^{2}\right)^{3 / 2}}\left[\alpha_{f} \sqrt{\alpha_{f}^{2}-1}-\cosh ^{-1} \alpha_{f}\right], \alpha_{f} \geq 1 \\
\frac{\alpha_{f}}{\left(1-\alpha_{f}^{2}\right)^{3 / 2}}\left[-\alpha_{f} \sqrt{\alpha_{f}^{2}-1}-\cosh ^{-1} \alpha_{f}\right], \alpha_{f} \leq 1
\end{array}\right.
\end{aligned}
$$

where $\alpha_{f}$ is the fiber aspect ratio. For composites materials with randomly oriented spheroids, the MT-based model of WangPyrz (Wang \& Pyrz, 2004) gives acceptable approximations for the overall bulk modulus and shear modulus, as given by the below equations:

$$
\begin{aligned}
& K=K_{m}+K_{m} \frac{\phi \varphi}{1-\phi(1-\alpha)} \\
& \mu=\mu_{m}+\mu_{m} \frac{\phi \psi}{1-\phi(1-\beta)}
\end{aligned}
$$

where $\alpha, \beta, \varphi$ and $\psi$ are coefficients given in terms of the components of Eshelby tensor (Hu et al., 2010; Wang \& Pyrz, 2004). The MT method was used in conjunction with molecular dynamic simulations to develop constitutive models for SWCNT reinforced polymer composites, considering the nanotube, local polymer near nanotube and nanotube/polymer interphase as a single equivalent fiber phase (Odegard et al. 2003). Additionally, the tensile stiffness properties for nano-clay platelets reinforced composites were calculated by Sheng et al. (Sheng et al., 2004) using MT and Halpin-Tsai, where the effects of nano-clay on the surrounding matrix was considered via anisotropic matrix layers around the particles; MT results were closer to the experimental ones than Halpin-Tsai results. Shao et al. (Shao, Luo, Bai, \& Wang, 2009) used the MT method to study the influence of the CNT concentration and waviness factor on the effective moduli of nano-composites. Moreover, the effects of carbon nanotube (CNT) incorporation within neat epoxy resin (nano-composites) and carbon fabricepoxy composites (multi-scale composites) were studied by Kim et al. (2011) using an approach that combines woven fiber micromechanics and the MT model; differences between the theoretical and experimental results were attributed to CNTs agglomerations and poor interfacial bonding. The MT method was also utilized by Aragh et al. (2012) considering the effects of nano-fillers agglomeration on the natural frequency of functional graded carbon nanotube-reinforced (FG-CNTR) nanocomposite panels. Sedeghpour et al. (2020) used the MT model to obtain the constitutive equations of CNTR nano-composites containing wavy CNTs, in order to study the influence of the interphase nano-fillers/matrix on the thermo-mechanical buckling behavior of the composite. Additionally, the influence of the volume content, orientation, distribution along thickness and misalignment of carbon nanotubes on the post-buckling behavior of functionally graded CNTs reinforced composites panels under uniaxial compression was analyzed by García-Macías et al. (2017) using the MT model. Bearing in mind the high applicability of the MT model, this is employed in the present work, with the corresponding equations shown later.

In the present work, a methodology is proposed to calculate the effective Young modulus of CNTs reinforced polymer matrix composites considering a probability distribution function for the dispersion degree and orientation; this function obeys to the one previously used by Isaza et al. (2018) and its fitting parameters are determined here using transmission electronic 
microscope (TEM) and in-plane image analysis. A three-phase Representative Elementary Volume, REV, is considered to relate the volume content of the three phases (equivalent fiber phase, fiber-matrix interphase and matrix), and the global MWCNTs volume and weight content with the free-path distance, fiber orientation and probability distribution functions experimentally obtained. The MWCNTs are conceived as an equivalent fiber phase with effective properties calculated by previously reported models ( Kumar \& Srinivas, 2018; Wu et al. 2006; Zhang \& Wang, 2005). Additionally, an average Young modulus is assumed for the fiber/matrix interface deeming its low thickness and following a formerly published model (Hu et al., 2014). Afterwards, the classical three-phase MT model is used to obtain the composite stiffness matrix considering perfectly aligned nanotubes with a dispersion degree quantified by the free-path distance. Using the plane-stress reduced stiffness coefficients and the transformation equations, effective modulus is expressed in terms of the orientation and freepath distance of nanotubes, and then, adopting the Cox's concept of integration, a non-linear double integral is obtained for the effective Young modulus, which is solved by means of the Monte-Carlo method. Numerical results obtained for the equivalent Young modulus of the MWCNTs and the effective Young modulus of the MWCNT/PVA composite are compared with experimental results achieved by micro-Raman spectroscopy and nano-indentation tests. Additionally, the proposed methodology is used to analyze the influence of the nanotube type (single wall, double wall and multi wall) and polymer matrix (PVA, PEEK and UHMWPE) on the effective Young modulus for different CNTs weight contents. The present methodology allows integrating statistical characterization parameters of dispersion degree and orientation of CNT reinforced composites with the MT model used in the calculation of the effective properties of aligned fibers reinforced composites, to predict the effective elastic modulus of stretched and non-stretched nano-composites materials.

\section{Analytical modelling for effective Young modulus of nano-composite}

\subsection{Geometric characterization of Representative Elementary Volume (REV)}

The REV defined in this model for the composite system is shown in Fig. 1. Three phases can be clearly identified: the MWCNT, named the equivalent fiber phase $(f)$, which includes both the carbon layers and gaps between them; the fibermatrix interphase $(\mathrm{fm})$ and the matrix phase $(\mathrm{m})$. The in-plane MWCNTs dispersion is quantified by the free-path distance, $r^{*}$, which is experimentally measured in the present work as shown later. On the other hand, the out-of-plane free-path distance, $r_{\text {out }}^{*}$, is not experimentally characterized, but computed in such way that the global MWCNT weight content in the REV is in agreement with values obtained in the experiments. Considering the REV orientation with respect to the global axes, " $x$ " and " $y$ ", where in-plane dispersion characterization is carried out, the volume content of the equivalent fiber phase $\left(v_{f}\right)$, fiber-matrix interphase $\left(v_{f m}\right)$ and matrix phase $\left(v_{m}\right)$ can be computed as follows:

$$
\begin{aligned}
& v_{f}=\frac{\pi \cdot r_{f}^{2} \cdot L_{C N T}}{\left(L_{C N T}+r^{*} g(\theta)\right)\left(2 r_{f}+r^{*} g(\theta)\right)\left(2 r_{f}+r_{\text {out }}^{*}\right)} \\
& v_{f m}=\frac{\pi\left[\left(r_{f}+t_{f m}\right)^{2}-r_{f}^{2}\right] L_{C N T}}{\left(L_{C N T}+r^{*} g(\theta)\right)\left(2 r_{f}+r^{*} g(\theta)\right)\left(2 r_{f}+r_{\text {out }}^{*}\right)} \\
& v_{m}=1-v_{f}-v_{f m}
\end{aligned}
$$

where $L_{C N T}$ is the nanotube length, $r_{f}$ is the outermost radius of equivalent fiber phase and $t_{f m}$ is the thickness of fiber-matrix interphase. On the other hand, the function $g(\theta)$ accounts for the REV orientation, in such a way that $g(\theta)=\cos (\theta)$ for $\theta \leq$ $45^{\circ}$ and $g(\theta)=\sin (\theta)$ for $\theta>45^{\circ}$. As abovementioned, the out-of-plane free-path distance, $r_{\text {out }}^{*}$, is recursively estimated to reproduce the global MWCNT weight content obtained by experiments. Accordingly, if $r_{\text {out }}^{*}$ is considered a scaled variable of the in-plane free-path distance, $r^{*}$, namely, $r_{o u t}^{*}=\alpha \cdot r^{*}$, with $\alpha$ as the scale factor, the global MWCNT volume fraction of a composite sample, as conceived as the weighted-average of the volume fractions of several REV's with fixed values of $r^{*}$ and $\theta$, can be computed using the statistical distribution functions for the dispersion degree and orientation, $f_{r^{*}} \mathrm{y} f_{\theta}$, as follows:

$$
\begin{aligned}
& v_{M W C N T, \text { global }}=\int_{r_{\text {inf }}^{*}}^{r_{\text {sup }}^{*}} \int_{\theta_{\text {inf }}}^{\theta_{\text {sup }}} v_{f}\left(r^{*}, \theta\right) f_{\theta^{*}} f_{r^{*}} d \theta d r^{*}= \\
& \int_{r_{\text {inf }}^{*}}^{r_{\text {sup }}^{*}} \int_{\theta_{\text {inf }}}^{\theta_{\text {sup }}}\left[\frac{\pi \cdot r_{f}^{2} \cdot L_{C N T}}{\left(L_{C N T}+r^{*} g(\theta)\right)\left(2 r_{f}+r^{*} g(\theta)\right)\left(2 r_{f}+\alpha r^{*}\right)}\right] f_{\theta^{*}} f_{r^{*}} d \theta d r^{*}
\end{aligned}
$$

where a log-normal distribution is considered for $r^{*}$ and $\theta$, as given by:

$$
f_{x}=\left\{\begin{array}{c}
\frac{1}{\mathrm{xn} \sqrt{2 \pi}} \exp \left[-\frac{1}{2}\left(\frac{\ln x-m}{\mathrm{n}}\right)^{2}\right], \text { for } \mathrm{x}>0 \\
0, \text { for } \mathrm{x} \leq 0
\end{array}\right.
$$


where $\mathrm{x}=\left[r^{*}, \theta\right], \mathrm{m}=\ln \left(\mathrm{u}^{2} / \sqrt{\mathrm{u}^{2}+\sigma^{2}}\right)$ and $\mathrm{n}=\sqrt{\ln \left[\left(\mathrm{u}^{2}+\sigma^{2}\right) / \mathrm{u}^{2}\right]}$, with $\mathrm{u}$ and $\sigma$ as the mean and standard deviation, respectively.

On the other hand, the global MWCNT weight content with respect to the matrix, is given by:

$$
w_{M W C N T, \text { global }}=\frac{W_{M W C N T}}{W_{m}}
$$

where $W_{M W C N T}$ and $W_{m}$ stand for the weight of MWCNTs and matrix, respectively. In the REV, the weight of the layered MWCNT can be computed as follows:

$$
W_{M W C N T}=V_{e f f} \cdot \rho_{g}
$$

In Eq. (32), $\rho_{g}$ is the graphite layer density and $V_{e f f}$ is the effective volume of the MWCNT given by:

$$
V_{e f f}=\pi\left[\left(2 r_{i} t_{C N T}+t_{C N T}^{2}\right) N_{C N T}+d_{C N T} t_{C N T} N_{C N T}\left(N_{C N T}-1\right)\right] L_{C N T}
$$

where $r_{i}$ is the innermost radius of the MWCNT, $t_{C N T}$ is the layer thickness, $N_{C N T}$ is the number of layers and $d_{C N T}$ is the distance between the layers centerlines (See Fig. 1). Given that the matrix weight can be computed as $W_{m}=$ $\rho_{m}\left(V_{R E V}-V_{e f f}\right)$, with $\rho_{m}$ and $V_{R E V}$ as the matrix density and the REV volume, respectively, and substituting Eq. (32) into Eq. (31), the next expression is obtained for the MWCNT weight content:

$$
w_{M W C N T, \text { global }}=\frac{V_{e f f} \cdot \rho_{g}}{\rho_{m}\left(V_{R E V}-V_{e f f}\right)}
$$

The global MWCNT volume fraction statistically computed in Eq. (29) can be defined as follows:

$$
v_{M W C N T, \text { global }}=\frac{V_{M W C N T}}{V_{R E V}}
$$

where $V_{M W C N T}$ is the MWCNT equivalent phase volume in the REV, as calculated by $V_{M W C N T}=\pi r_{f}^{2} L_{C N T}$. On the other hand, the ratio of $V_{M W C N T}$ to $V_{\text {eff }}$, considering Eq. (33), can be computed as:

$$
\frac{V_{M W C N T}}{V_{e f f}}=\frac{r_{f}^{2}}{\left(2 r_{i} t_{C N T}+t_{C N T}{ }^{2}\right) N_{C N T}+d_{C N T} t_{C N T} N_{C N T}\left(N_{C N T}-1\right)} .
$$

Solving for $V_{M W C N T}$ in Eq. expression is achieved:

$$
\frac{V_{e f f}}{V_{R E V}}=\left[\frac{\left(2 r_{i} t_{C N T}+t_{C N T}{ }^{2}\right) N_{C N T}+d_{C N T} t_{C N T} N_{C N T}\left(N_{C N T}-1\right)}{r_{f}^{2}}\right] v_{M W C N T, \text { global }}
$$

Eq. (34) can be rewritten as follows:

$$
w_{M W C N T, \text { global }}=\frac{\left(V_{e f f} / V_{R E V}\right) \cdot \rho_{g}}{\rho_{m}\left(1-V_{e f f} / V_{R E V}\right)}
$$

Solving for $V_{e f f} / V_{R E V}$ in Eq. (38), substituting into (37) and then solving for $v_{M W C N T, \text { global }}$, an expression is obtained for the nanotube volume fraction of the composite in terms of geometrical characteristics of the MWCNTs $\left(r_{f}, r_{i}, t_{C N T}, d_{C N T}, N_{C N T}\right)$, densities of constituents materials $\left(\rho_{m}, \rho_{g}\right)$ and nanotube weight content with respect to matrix $\left(w_{M W C N T, \text { global }}\right)$ :

$$
v_{M W C N T, \text { global }}=\frac{r_{f}^{2}}{\left(2 r_{i} t_{C N T}+t_{C N T}\right)^{2} N_{C N T}+d_{C N T} t_{C N T} N_{C N T}\left(N_{C N T}-1\right)} \cdot \frac{w_{M W C N T, \text { global }} \cdot \rho_{m}}{w_{M W C N T, \text { global }} \cdot \rho_{m}+\rho_{g}}
$$

Matching Eq. (29) and Eq. (39), the following equation is obtained:

$$
\begin{aligned}
& \int_{r_{\text {inf }}^{*}}^{r_{\text {sup }}^{*}} \int_{\theta_{\text {inf }}}^{\theta_{\text {sup }}}\left[\frac{\pi \cdot r_{f}^{2} \cdot L_{C N T}}{\left(L_{C N T}+r^{*} g(\theta)\right)\left(2 r_{f}+r^{*} g(\theta)\right)\left(2 r_{f}+\alpha r^{*}\right)}\right] f_{\theta^{*}} f_{r^{*}} d \theta d r^{*}= \\
& \frac{r_{f}^{2}}{\left(2 r_{i} t_{C N T}+t_{C N T}{ }^{2}\right) N_{C N T}+d_{C N T} t_{C N T} N_{C N T}\left(N_{C N T}-1\right)} \cdot \frac{w_{M W C N T, \text { global }} \cdot \rho_{m}}{w_{M W C N T, \text { global }} \rho_{m}+\rho_{g}}
\end{aligned}
$$


Eq. (40) can be solved for the scale parameter $\alpha$ using the regula-falsi method, where the double integral can be computed by Monte Carlo method as explained in Section 2.3.

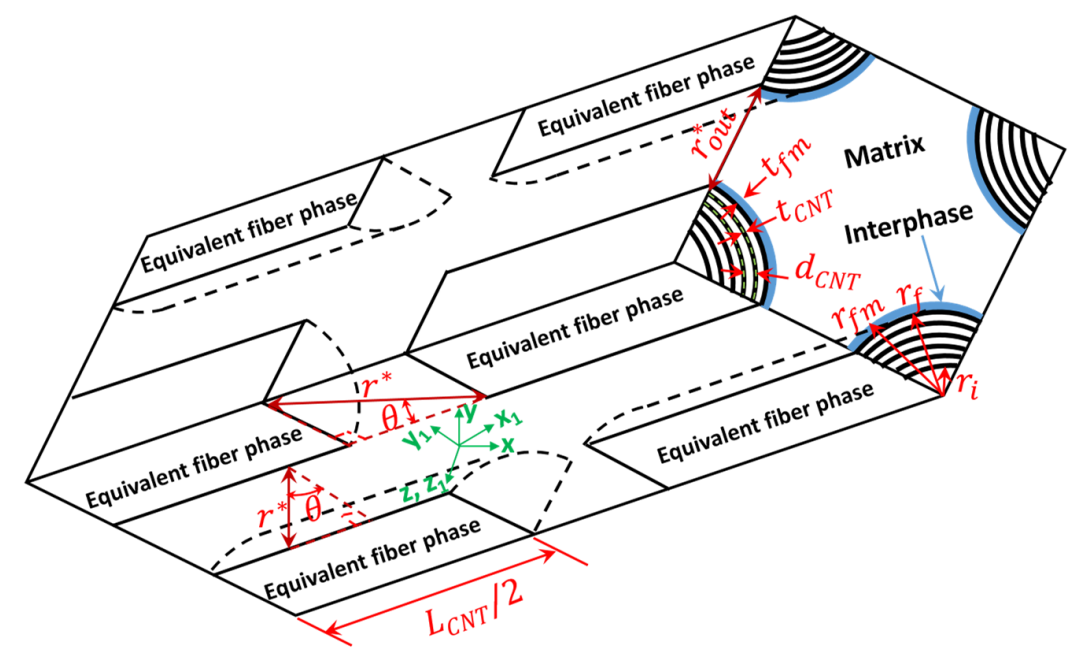

Fig. 1. Scheme of the Representative Elementary Volume (REV).

\subsection{Mori-Tanaka approach for the effective Young modulus}

The effective elastic properties of MWCNTs (equivalent fiber phase) depends on the elastic properties of graphite layers, number and thickness of walls, and the wall spacing. The effective Young modulus, $E_{f}$, and shear modulus, $G_{f}$, can be computed as follows (Kumar \& Srinivas, 2018; Wu et al., 2006; Zhang \& Wang, 2005):

$$
\begin{aligned}
E_{f} & =\frac{N_{C N T} \cdot t_{C N T} \cdot E_{g}}{\left(N_{C N T}-1\right) \cdot d_{C N T}+t_{C N T}} \\
G_{f} & =\frac{E_{f}}{2\left(1+v_{f}\right)}
\end{aligned}
$$

where $E_{g}$ is the Young modulus of a graphite layer and $v_{f}$ is the Poisson's ratio of the MWCNT (equivalent fiber phase). On the other hand, Young modulus at the fiber-matrix interphase changes in radial direction as shown below (Hu et al., 2014):

$$
E_{f m}(r)=E_{m}\left(\frac{r_{f m}}{r}\right)+\left(\frac{r_{f m}-r}{t_{f m}}\right)^{k}\left(E_{f}-E_{m} \frac{r_{f m}}{r_{f}}\right)
$$

where $k$ is the interphase enhancement index. Considering that the fiber-matrix interphase is usually very thin, the average value of $E_{f m}(r)$ can be taken into account, as defined by:

$$
E_{f m}=\frac{2}{r_{f m}^{2}-r_{f}^{2}} \int_{r_{f}}^{r_{f m}} E_{f m}(r) \cdot r \cdot d r
$$

After integrating Eq. (44), the following expression is achieved for the average Young modulus at the fiber-matrix interphase:

$$
E_{f m}=\frac{2}{r_{f m}^{2}-r_{f}^{2}}\left[E_{m} r_{f m} t_{f m}+\left(E_{f}-E_{m} \frac{r_{f m}}{r_{f}}\right)\left(\frac{t_{f m}\left(k \cdot r_{f}+r_{f m}+r_{f}\right)}{(k+1)(k+2)}\right)\right]
$$

According to Hu et al. (2014), an acceptable approximation for the average Poisson's ratio of the fiber-matrix interphase is considering the Poisson's ratio of matrix, i.e., $v_{f m} \approx v_{m}$. Then, the average shear modulus of the fiber-matrix interphase, bearing in mind this is deemed isotropic, can be calculated as follows:

$$
G_{f m}=\frac{E_{f m}}{2\left(1+v_{f m}\right)}
$$

As abovementioned, multi-walled carbon nanotubes (MWCNTs) can be considered as inclusions in the composite matrix. Considering perfectly aligned inclusions, the Mori-Tanaka three phase model (Dunn \& Ledbetter, 1995; Kundalwal, 2018) can be used to compute the composite stiffness matrix, $[C]$, as defined by: 


$$
[C]=\left[v_{m}\left[C^{m}\right][I]+v_{f}\left[C^{f}\right]\left[A^{f}\right]+v_{f m}\left[C^{f m}\right]\left[A^{f m}\right]\right] \cdot\left[v_{m}[I]+v_{f}\left[A^{f}\right]+v_{f m}\left[A^{f m}\right]\right]^{-1}
$$

where $v_{m}, v_{f}$ and $v_{f m}$ are the volume content of matrix, fiber and fiber-matrix interphase, respectively, whereas [ $\left.C^{m}\right]$, [ $\left.C^{f}\right]$ and $\left[C^{f m}\right]$ are the corresponding stiffness matrices, whose non-zero components, considering isotropic phases, can be computed as follows:

$$
\begin{aligned}
& C_{i i}^{S}=\Lambda_{s}\left(1-v_{s}\right) \quad \text { for } i=[1,2,3] \\
& C_{i i}^{S}=\frac{\Lambda_{s}}{2}\left(1-2 v_{s}\right) \text { for } i=[4,5,6] \\
& C_{i j}^{S}=v_{s} \text { for }(i, j)=[(1,2) ;(1,3) ;(2,3) ;(2,1) ;(3,1) ;(3,2)]
\end{aligned}
$$

In Eq. (48) to Eq. (50), the script "s" stands for the phase, i.e., $s=[m, f, f m]$. Accordingly, $v_{s}$ is the Poisson ratio of the phase "s" and the constant $\Lambda_{s}$ is defined in terms of this property and the Young modulus, $E_{s}$, as follows:

$$
\Lambda_{s}=\frac{E_{S}}{\left(1+v_{s}\right)\left(1-2 v_{s}\right)}
$$

On the other hand, in Eq. (47), the stress concentration tensors, $\left[A_{f}\right]$ and $\left[A_{f m}\right]$, are given by the following equations:

$$
\begin{aligned}
& {\left[A_{f}\right]=\left[[I]+\left[S^{f}\right]\left\{\left(\left[C^{m}\right]^{-1}\right) \cdot\left(\left[C^{f}\right]-\left[C^{m}\right]\right)\right\}\right]^{-1}} \\
& {\left[A_{f m}\right]=\left[[I]+\left[S^{f m}\right]\left\{\left(\left[C^{m}\right]^{-1}\right) \cdot\left(\left[C^{f m}\right]-\left[C^{m}\right]\right)\right\}\right]^{-1}}
\end{aligned}
$$

where the non-zero components of the Eshelby tensor for the equivalent fiber phase, $\left[S^{f}\right]$, and fiber-matrix interphase, $\left[S^{f m}\right]$, are calculated as follows (Qiu \& Weng, 1990)

$$
\begin{aligned}
& S_{i i}^{S}=\frac{5-4 v_{S}}{8\left(1-v_{s}\right)}, i=2,3 \\
& S_{44}^{S}=\frac{3-4 v_{S}}{8\left(1-v_{S}\right)} \\
& S_{i i}^{S}=\frac{1}{4}, i=5,6 \\
& S_{i 1}^{S}=\frac{v_{S}}{2\left(1-v_{s}\right)}, i=2,3 \\
& S_{i j}^{S}=\frac{4 v_{S}-1}{8\left(1-v_{S}\right)}, \quad(i, j)=[(2,3) ;(3,2)]
\end{aligned}
$$

With $s=[f, f m]$. The effective compliance matrix of composite, $[S]$, can be computed as the inverse of the stiffness matrix, $[S]=[C]^{-1}$, and thereupon, the plane-stress reduced stiffness coefficients can be computed as follows:

$$
\begin{aligned}
& Q_{11}=\frac{S_{22}}{S_{11} S_{22}-\left(S_{12}\right)^{2}} \\
& Q_{12}=\frac{S_{12}}{S_{11} S_{22}-\left(S_{12}\right)^{2}} \\
& Q_{22}=\frac{S_{11}}{S_{11} S_{22}-\left(S_{12}\right)^{2}} \\
& Q_{66}=\frac{1}{S_{66}}
\end{aligned}
$$

Eq. (59) to Eq. (62) apply when local coordinate system shown in Fig. 1, $\left(x_{1}, y_{1}, z_{1}\right)$, matches the global coordinate system, $(x, y, z)$. When nanotubes are oriented at angle $\theta$ from $x$, the effective Young modulus in the $x$ direction can be computed as follows (Reddy, 2003):

$$
\begin{aligned}
& E_{x}\left(r^{*}, \theta\right)=Q_{11}\left(v_{f}\left(r^{*}\right)\right) \cdot \cos ^{4}(\theta)+2 \cdot\left[Q_{12}\left(v_{f}\left(r^{*}\right)\right)+\right. \\
& \left.2 Q_{66}\left(v_{f}\left(r^{*}\right)\right)\right] \cdot \sin ^{2}(\theta) \cdot \cos ^{2}(\theta)+Q_{22}\left(v_{f}\left(r^{*}\right)\right) \cdot \sin ^{4}(\theta)
\end{aligned}
$$


An expression for the effective Young modulus in terms of the free-path distance, $r^{*}$, and the orientation angle of CNTs, $\theta$, is obtained in eq. (63). The effective Young modulus of the composite, $E_{x}$, can be statistically estimated using the distribution functions for nanotubes dispersion, $f_{r^{*}}$, and nanotubes orientation, $f_{\theta^{*}}$, as given by:

$$
E_{x}=\int_{r_{\text {inf }}^{*}}^{r_{\text {sup }}^{*}} \int_{\theta_{\text {inf }}}^{\theta_{\text {sup }}} E_{x}\left(r^{*}, \theta\right) f_{\theta^{*}} f_{r^{*}} d \theta d r^{*}
$$

\subsection{Monte Carlo integration}

Analytical solution of integrals shown in eqs. (29) and (64) is not straightforward since integrands are highly non-linear. Non-uniform stratified Monte Carlo integration method is implemented here, with the integral estimator computed as follows:

$$
\left\langle G^{N_{r^{*}, N_{\theta}}}\right\rangle=\frac{1}{N_{r^{*} \cdot N_{\theta}}} \sum_{i=0}^{N_{r^{*}-1}} \sum_{j=0}^{N_{\theta}-1} \frac{g\left(r_{i}^{*}, \theta_{j}\right)}{p d f\left(r_{i}^{*}\right) \cdot p d f\left(\theta_{j}\right)}
$$

where $N_{r^{*}}$ and $N_{\theta}$ stand for the number of divisions in $r^{*}$ and $\theta$, whereas $p d f\left(r_{i}^{*}\right)$ and $p d f\left(\theta_{j}\right)$ are the probability density functions in point $r_{i}^{*}$ and $\theta_{j}$, respectively, which in this case can be approximated as follows:

$$
\begin{aligned}
& p d f\left(r_{i}^{*}\right)=\frac{1}{N_{r^{*}}\left(r_{\text {sup }}^{*}{ }^{(i)}-r_{\text {inf }}^{*}{ }^{(i)}\right)} \\
& \operatorname{pdf}\left(\theta_{j}\right)=\frac{1}{N_{\theta}\left(\theta_{\text {sup }}{ }^{(j)}-\theta_{\text {inf }}{ }^{(j)}\right)}
\end{aligned}
$$

With $r_{\text {sup }}^{*}{ }^{(i)}$ and $r_{\text {inf }}^{*}{ }^{(i)}$ as the superior and inferior limit of strata $" i "$ in $r^{*}$, and $\theta_{\text {sup }}{ }^{(j)}$ and $\theta_{\text {inf }}{ }^{(j)}$ as the corresponding limits of strata " $j "$ in $\theta$. In the present work, the strata do not have a uniform size since a higher strata density should be considered in zones where gradients of the function $g\left(r^{*}, \theta\right)$ are significant. Function $g\left(r^{*}, \theta\right)$ corresponds to the integrand of the integral to be solved, in such a way that for (29) and (64), this function is given by (68) and (69), respectively.

$$
\begin{aligned}
& g\left(r^{*}, \theta\right)=\left[\frac{\pi \cdot r_{f}^{2} \cdot L_{C N T}}{\left(L_{C N T^{+}}+r^{*} g(\theta)\right)\left(2 r_{f}+r^{*} g(\theta)\right)\left(2 r_{f}+\alpha r^{*}\right)}\right] f_{\theta^{*}} f_{r^{*}} \\
& g\left(r^{*}, \theta\right)=E_{x}\left(r^{*}, \theta\right) f_{\theta^{*}} f_{r^{*}}
\end{aligned}
$$

In Fig. 2a, it is shown a typical integrand function, $g\left(r^{*}, \theta\right)$, considered in the present work for the calculation of the effective Young modulus, with the corresponding strata points represented in Fig. $2 \mathrm{~b}$.

a)

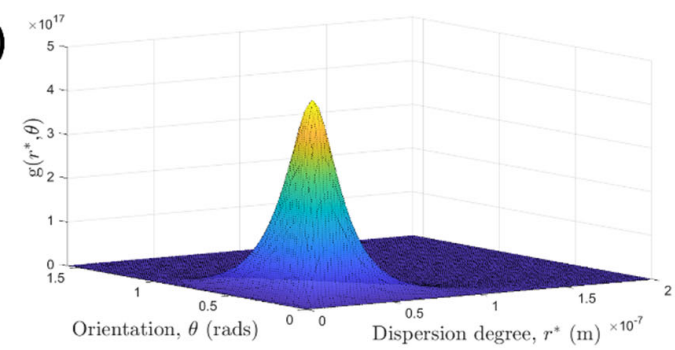

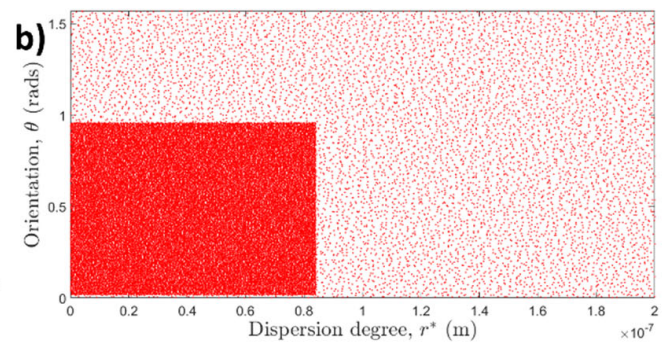

Fig. 2. a) Integrand function, $g\left(r^{*}, \theta\right)$, for the effective Young modulus calculation of MWCNT/PVA composite with $0.5 \%$ w.t and stretched, Outer Diameter of $20 \mathrm{~nm}$, Inner Diameter of $5 \mathrm{~nm}$, Length of $30 \mu \mathrm{m}$, Wall Thickness of $0.33 \mathrm{~nm}$, 14 walls, b) Corresponding space of strata points for a certain Monte Carlo simulation run, where a higher points density can be noticed in the larger gradient zones.

\section{Sample preparation and data characterization of the MWCNTs polymer composite}

\subsection{Polymer Matrix Composite Synthesis}

For the synthesis of the polymer matrix composite, pellets of fully hydrolyzed polyvinyl alcohol (PVA) were diluted in hot distilled water to produce a solution of $4 \mathrm{wt} . \%$ of PVA. MWCNTs were introduced into the PVA solution in weight percentages of $0.25 \%, 0.5 \%$ and $1.0 \%$, and they were dispersed by magnetic stirring during 1 hour at an average speed of $600-900 \mathrm{rpm}$, followed by a sonication, which was set to a power of $100 \mathrm{~W}$ and an amplitude of the probe of $20 \%$; the maximum energy of dispersion was 60 - $70 \mathrm{~kJ}$. Some cured composites were stretched using a Monsanto tensile machine at a speed of $1-2 \mathrm{~mm} / \mathrm{min}$ and at a temperature of $60^{\circ} \mathrm{C}$, in order to align the MWCNTs into the polymeric matrix. Therefore, two sets of samples were obtained: non-stretched (alignment process is not applied) and stretched (samples are slowly elongated). 


\subsection{Dispersion and orientation quantification of MWCNTs in PVA matrix}

In this work, both the dispersion and orientation quantification were done using the same methodology. The samples were sectioned parallel to the stretching direction by a RMC Boeckeler PT-PC Power Tome ultra-microtome using a diamond knife; films of about $200 \mathrm{~nm}$ in thickness were obtained. One sample for each reinforcement weight percentage was used for transmission electron microscopy (TEM) characterization in scanning mode. Representative images of $1 \times 1 \mu \mathrm{m}$ were divided into 10x10 grid lines along the horizontal and vertical directions and the spacing, both horizontal and vertical, between nearest MWCNTs was measured at each grid intersection using the free software Gwyddion (see Fig. 3a). These images were also used to quantify the orientation degree of the reinforcement, namely, the angle of each MWCNT with respect to the stretching direction was measured (see Fig. 3b). These data were used to obtain the mean and standard deviation of the probability distribution function given in (Luo \& Koo, 2007), which is shown in (30). In the lower part of Fig. 3a and 3b, representative images show some probability distribution functions for MWCNTs dispersion and orientation into the polymeric matrix.
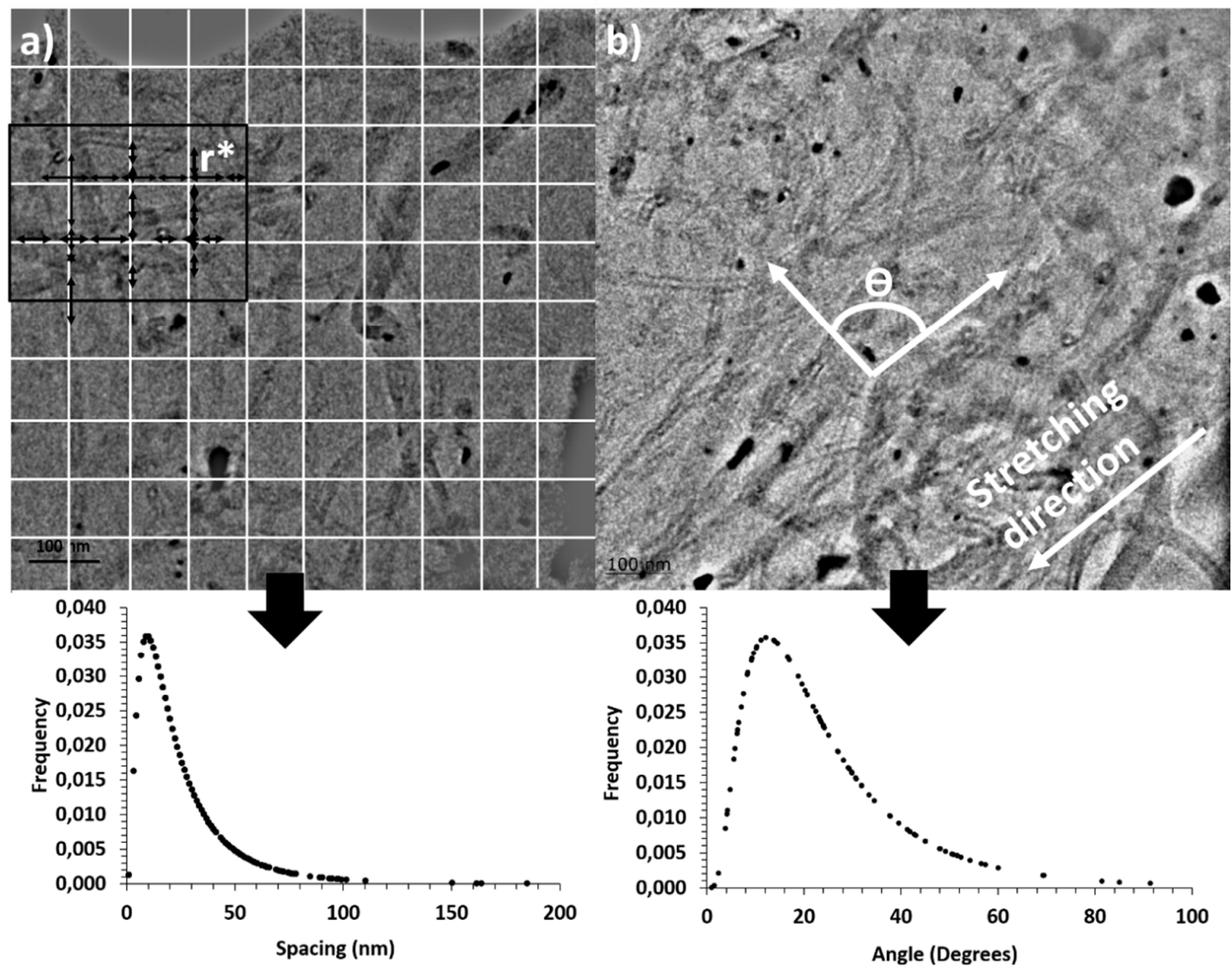

Fig. 3. a) Dispersion and b) orientation quantification of MWCNTs into polymeric matrix.

Considering the mean $(u)$ and standard deviation $(\sigma)$ of the log-normal distribution function showed in eq. (30), a parameter $\mathrm{D}_{0.1}$, defined as the probability computed in the range between (0.9)u and (1.1) $u$, can be estimated using Eq. (70). This parameter accounts for the data deviation from the mean, $u$, in such a way that for an ideal case of $\mathrm{D}_{0.1}=100 \%$, the nanotubes would be almost equally spaced and oriented in the composite.

$$
\begin{aligned}
& \mathrm{D}_{0,1}=1,1539 \times 10^{-2}+7,5933 \times 10^{-2} *\left(\frac{\mathrm{u}}{\sigma}\right)+6,6838 \times 10^{-4}\left(\frac{\mathrm{u}}{\sigma}\right)^{2}-1,9169 \times 10^{-4}\left(\frac{\mathrm{u}}{\sigma}\right)^{3}+3,9201 \times \\
& 10^{-6}\left(\frac{\mathrm{u}}{\sigma}\right)^{4}
\end{aligned}
$$

Statistical parameters experimentally obtained for the free-path distance, $r^{*}$, and orientation, $\theta$, are shown in Table 1 . Two aspects are clearly noticed for the free-path distance, $r^{*}$ : both the average value $(u)$ and the deviation parameter $\left(\mathrm{D}_{0.1}\right)$ increases with the alignment process, which is expected because the MWCNTs try to follow the rotation of the polymeric chains, thus pushing them away. This effect is lower as the concentration of MWCNTs increases; once again this is expected since the composite becomes stiffer with the addition of the reinforcing material, which turns the chains rotation more difficult. In consequence, the distances between the MWCNTs are shorter when the reinforcement content is increased. For the orientation, Table 1 shows that the most common angles for the stretched composites are around 20 degrees for all MWCNT weight contents, which correspond to a small angle with respect to the stretching direction after the alignment process, indicating an acceptable alignment process. 
Table 1. Measured and calculated parameters for the PVA/MWCNTs composite

\begin{tabular}{|c|c|c|c|c|c|c|}
\hline \multirow[b]{2}{*}{ Sample (wt.\% MWCNTs) } & \multicolumn{3}{|c|}{ DISPERSION } & \multicolumn{3}{|c|}{ ORIENTATION } \\
\hline & $\begin{array}{l}\text { Average free } \\
\text { path }\left(\mathrm{r}^{*}\right)(\mathrm{nm})\end{array}$ & Standard deviation (nm) & $\mathrm{D}_{0.1}(\%)$ & Average $(\theta)$ & $\begin{array}{c}\text { Standard deviation } \\
(\theta)\end{array}$ & $\mathrm{D}_{0.1}(\%)$ \\
\hline PVA- 0.25 Non stretched & 34.5 & 26.7 & 8.8 & - & - & - \\
\hline PVA-0.25 Stretched & 62.5 & 54.7 & 8.9 & 29.1 & 20.7 & 10.7 \\
\hline PVA- 0.5 Non stretched & 27.7 & 25.5 & 7.1 & - & - & - \\
\hline PVA-0.5 Stretched & 58.6 & 44.0 & 10.3 & 28.3 & 23.4 & 8.3 \\
\hline PVA-1.0 Non stretched & 22.8 & 16.4 & 10.4 & - & - & - \\
\hline PVA-1.0 Stretched & 30.0 & 21.0 & 10.6 & 39.7 & 29.8 & 9.0 \\
\hline
\end{tabular}

\subsection{MWCNTs Young modulus quantification}

The Young modulus of the MWCNTs was measured to evaluate the accuracy of the micromechanical model used in the present work, see Eq. (41). The micro-Raman spectroscopy method was used for such a purpose. The method is used to monitor the cooling-induced compressive deformation of MWCNTs embedded in the PVA matrix. The Young modulus of multi-walled carbon nanotubes may then be derived from a concentric cylinder model considering thermal stresses, using the D*-band shift for each tube type.

The Raman spectra for the constituent materials and composite PVA/MWCNTs are shown in Fig. 4a, where the principal Raman peaks for the PVA, MWCNTs and PVA/MWCNTs composite can be identified. The principal peak of the PVA takes place at a frequency of $2911.14 \mathrm{~cm}^{-1}$, which does not interfere with the MWCNT D*-band shift, whose peak is reached at frequency of $2700 \mathrm{~cm}^{-1}$ approximately; that is located for measuring the displacement due to the cooling process.

The displacement of the $\mathrm{D}^{*}$-band was measured before and after the cooling process. For the PVA/MWCNTs, a shift of the $\mathrm{D}^{*}$-band of $6 \mathrm{~cm}^{-1}$ to higher frequencies was observed after a quenching process at $-180^{\circ} \mathrm{C}$ (Fig. $4 \mathrm{~b}$ ) Since the shift occurred toward higher frequencies, this is interpreted as a compression of the C-C bonds (Huong et al., 1995), which might result from the contraction of the PVA upon polymerization, which in turn reflects the cooling stresses generated by the contraction of the PVA.
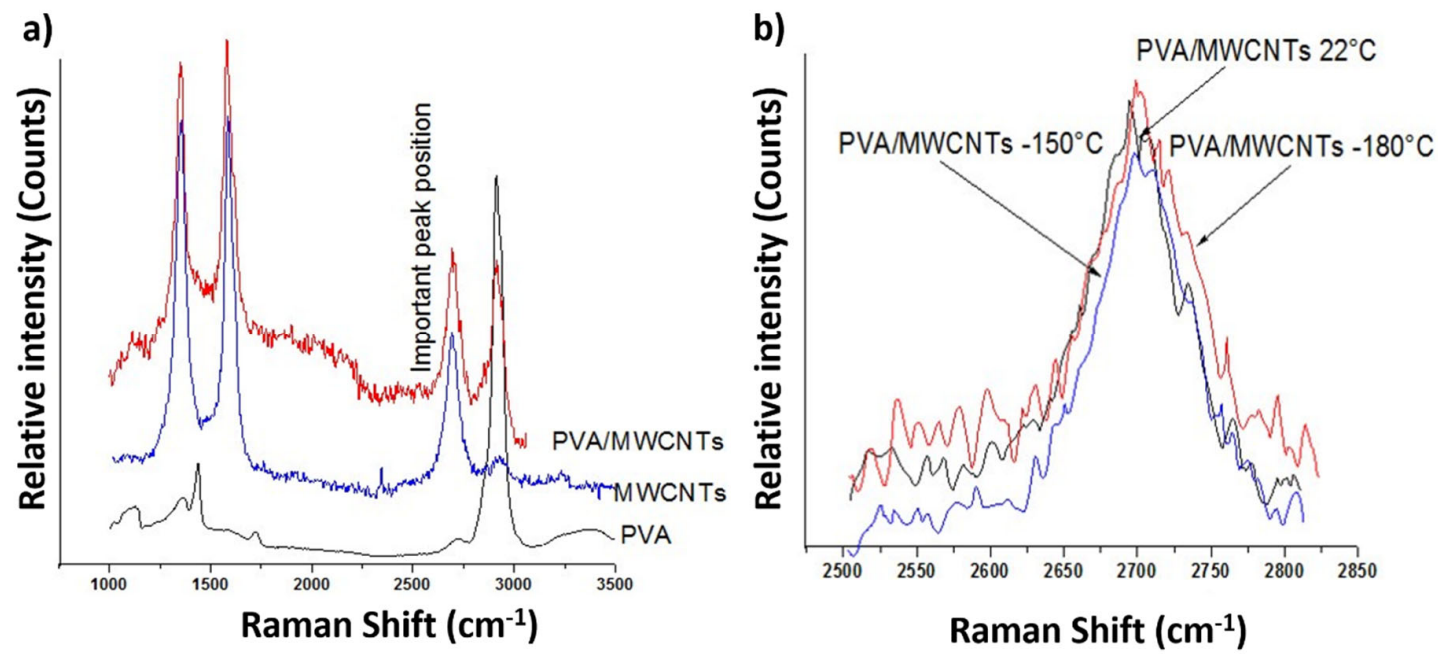

Fig. 4. a) Raman spectra for PVA, MWCNTs and PVA/MWCNTs and b) Effects of embedment and cooling on the frequency shift of the D*-band

With the information generated above and taking into account the linear dependence between the band shift and temperature explained in (Lourie \& Wagner, 1998), and the correlation between the band shift and the bond length shortening (Schaufele \& Shimanouchi, 1967), the compressive strain of the nanotube can be approximated as follows:

$$
\varepsilon_{C N T}=-\frac{\Delta l}{l}=\frac{\Delta w}{w}
$$

where 1 is the bond length and $w$ is the frequency. In that way, equation (72) can be formulated (Lourie \& Wagner, 1998):

$$
\varepsilon_{C N T}=-\left(1-\frac{w_{o}}{w_{q}}\right)
$$


where $w_{o}$ and $w_{q}$ are the bond frequencies before and after quenching, respectively. Using the concentric cylinder model described in (Wagner, 1996), the axial stress due to the cooling is given by:

$$
\sigma_{C N T}=\frac{\Delta \alpha \Delta T}{1+\frac{v_{f . C N T}\left(E_{C N T}\right)}{v_{f . m}\left(E_{m}\right)}} E_{C N T}
$$

where $\Delta \alpha$ is the difference between expansive coefficients of MWCNTs and PVA, $\Delta T$ is the difference between initial and final temperatures, $v_{f, C N T}$ and $v_{f, m}$ are the volumetric fraction of MWCNTs and PVA, respectively, and $E_{C N T}$ and $E_{m}$ are the elastic moduli for the MWCNTs and PVA matrix, correspondingly. Thereby, using the Hooke law for the nanotube, $\sigma_{C N T}=$ $E_{C N T} . \varepsilon_{C N T}$, in eq. (73), substituting eq. (72) for $\varepsilon_{C N T}$, and solving for $E_{C N T}$ in the resulting expression, it is possible to compute the elastic modulus of the MWCNTs as given in (74), whose data and results are given in Table 2.

$$
E_{C N T}=E_{m},\left[\frac{\Delta \alpha \Delta T+\left(1-\frac{w_{o}}{w_{q}}\right)}{-\left(1-\frac{w_{o}}{w_{q}}\right) \frac{V_{f . C N T}}{V_{f . m}}}\right]
$$

Table 2. Data and result for calculation of MWCNTs modulus by Raman spectroscopy

$\begin{array}{ccccccc}\Delta \text { TK } & \Delta \boldsymbol{\alpha} \text { K-1 } & \text { Vfcnt } & \text { Em (GPa) } & \mathbf{W}_{\mathbf{0}} & \mathbf{W}_{\mathbf{q}} & \text { ECNT(GPA) } \\ -202 & 0.000074 & 0.0021 & 0.3 & 2697,16 \pm 0.5 & 2703,9 \pm 0.5 & 881 \pm 105\end{array}$

\subsection{Data for numerical simulations}

The properties of the constituent materials used in the simulations are summarized in Table 3 . In the present work, three types of CNTs (single-walled, double-walled and multi-walled) and polymer matrices (PVA, PEEK-polyether ether ketone and UHMWPE- ultra high molecular weight polyethylene) are deemed in the numerical simulations. For single-walled carbon nanotubes (SWCNTs) and double-walled carbon nanotubes (DWCNTs), unique values are assigned for the outer diameter $\left(d_{\text {out }}\right)$, inner diameter $\left(d_{i n}\right)$ and wall thickness $\left(t_{C N T}\right)$ of nanotubes, in such a way that for SWCNTs, $\mathrm{d}_{\text {out }}=1.70 \mathrm{~nm}, \mathrm{~d}_{\text {in }}=1.04 \mathrm{~nm}$ and $\mathrm{t}_{\mathrm{CNT}}=0.33 \mathrm{~nm}$, whereas for DWCNTs, $\mathrm{d}_{\mathrm{out}}=7.5 \mathrm{~nm}, \mathrm{~d}_{\mathrm{in}}=5.7 \mathrm{~nm}$ and $\mathrm{t}_{\mathrm{CNT}}=0.33 \mathrm{~nm}$; for both CNTs types, a length between 30 to $40 \mu \mathrm{m}$ are considered. On the other hand, for a set of multi-walled carbon nanotubes (MWCNTs), dimensional variability is more relevant and several possible dimensions shall be considered.

Table 3. Properties of constituent materials of nano-composites

\begin{tabular}{lcccc}
\hline & Graphite layer & PVA & PEEK & UHMWPE \\
\hline Density $\left(\mathrm{Kg} / \mathrm{m}^{3}\right)$ & 2100 & 1170 & 1300 & 3.60 \\
Young modules $(\mathrm{GPa})$ & 1450 & 0.34 & 0.90 & 0.30 \\
Poisson ratio & 0.27 & 0.45 & 0.46 \\
\hline
\end{tabular}

MWCNTs used in the experiments were supplied by Nanostructured \& Amorphous Materials Inc. They are not exactly equal each other because of their synthesis process (Chemical Vapor Deposition-CVD); while arc discharge and ablation laser are methods that produce CNTs with a higher reproducibility, CVD produces CNTs with larger variability of their diameters and lengths (Dervishi et al., 2009). The length of MWCNTs used in this study ranges between 20 and 40 nm, inner diameter between 5 and $20 \mathrm{~nm}$, interlayer gap between 0.20 and $0.23 \mathrm{~nm}$, and wall thickness can be considered as $0.33 \mathrm{~nm}$. In the present work, they are considered five nanotube lengths in the numerical simulations, namely, $\mathrm{L}=[30,35,40,45,50] \mu \mathrm{m}$, and for each one of them, 21 possible combinations, which satisfy (75) for the interlayer gap $\left(h_{C N T}\right)$, are taken into account; these are shown in Table 4.

$$
h_{C N T}=\frac{\left(d_{o u t}-d_{i n}\right) / 2-t_{C N T} \cdot N_{C N T}}{N_{C N T}-1}
$$

where $h_{C N T}$ is the interlayer gap, $\mathrm{d}_{\text {out }}$ is the outer diameter, $\mathrm{d}_{\text {in }}$ is the inner diameter, $t_{C N T}$ is the wall thickness and $N_{C N T}$ is

\begin{tabular}{|c|c|c|c|c|c|c|c|c|c|c|c|c|c|c|c|c|c|c|c|c|c|}
\hline Property and units & \multicolumn{21}{|c|}{ Combinations } \\
\hline & 1 & 2 & 3 & 4 & 5 & 6 & 7 & 8 & 9 & 10 & 11 & 12 & 13 & 14 & 15 & 16 & 17 & 18 & 19 & 20 & 21 \\
\hline $\begin{array}{l}\text { Outer diameter, } \mathrm{d}_{\text {out }} \\
(\mathrm{nm})\end{array}$ & 20 & 25 & 25 & 25 & 30 & 30 & 30 & 30 & 30 & 35 & 35 & 35 & 35 & 35 & 35 & 35 & 40 & 40 & 40 & 40 & 40 \\
\hline $\begin{array}{l}\text { Inner diameter, } \mathrm{d}_{\mathrm{in}} \\
(\mathrm{nm})\end{array}$ & 5 & 5 & 7.5 & 10 & 5 & 7.5 & 10 & 12.5 & 15 & 5 & 7.5 & 10 & 12.5 & 15 & 17.5 & 20 & 10 & 12.5 & 15 & 17.5 & 20 \\
\hline $\begin{array}{l}\text { Wall thinkness of } \\
\mathrm{CNT}, t_{\mathrm{CNT}}(\mathrm{nm})\end{array}$ & \multicolumn{21}{|c|}{$33 \mathrm{E}-2$} \\
\hline $\begin{array}{l}\text { Interlayer gap, } \\
\mathrm{h}_{\mathrm{CNT}}(\mathrm{nm})\end{array}$ & \multicolumn{21}{|c|}{$22 \mathrm{E}-2$} \\
\hline $\begin{array}{l}\text { Number of walls, } \\
\text { N }\end{array}$ & 14 & 19 & 17 & 14 & 23 & 21 & 19 & 17 & 14 & 28 & 25 & 23 & 23 & 19 & 16 & 14 & 28 & 26 & 23 & 21 & 19 \\
\hline $\begin{array}{l}\text { Distance between } \\
\text { layers centerline, } \\
d_{\mathrm{CNT}(\mathrm{nm})}\end{array}$ & \multicolumn{21}{|c|}{$55 \mathrm{E}-2$} \\
\hline
\end{tabular}
the number of walls.

Table 4. Geometrical data of multi-walled carbon nanotubes for each nanotube length. 
As 21 combinations are considered for each nanotube length, a total of 105 combinations are taken into account to numerically characterize the REV and obtain the effective Young modulus of the nano-composite. Additionally, for each combination, 20 simulations are carried out, with the Monte Carlo integration strata points randomly generated in each simulation.

\section{Results and discussion}

\subsection{Comparison between experimental and numerical results}

The effective Young modulus $\left(E_{f}\right)$ and shear modulus $\left(\mathrm{G}_{\mathrm{f}}\right)$ of MWCNTs can be computed using eqs. (41) and (42), respectively, for each combination shown in Table 4, with the results represented in Table 5. For the former property, $\mathrm{E}_{\mathrm{f}}$, the average value and standard deviation are $\overline{E_{f}}=896.47 \mathrm{GPa}$ and $\sigma\left(E_{f}\right)=15.72 \mathrm{GPa}$, respectively. The relative difference between the average effective Young modulus, $\overline{E_{f}}$, and the mean experimental one obtained by micro-Raman spectroscopy, $E_{f, \text { exp }}$, see Table 2, defining this relative difference by $d_{r e l}=\left|\overline{E_{f}}-E_{f, \exp }\right| / E_{f, \exp }$, is $1.76 \%$, indicating the reliability of the micromechanical model used here. The average value for the effective shear modulus is $\overline{G_{f}}=352.94 \mathrm{GPa}$.

Table 5. Effective Young and shear moduli for the combinations of multi-walled carbon nanotubes

\begin{tabular}{|c|c|c|c|c|c|c|c|c|c|c|c|c|c|c|c|c|c|c|c|c|c|}
\hline \multirow[t]{2}{*}{ Property/units } & \multicolumn{21}{|c|}{ Combinations } \\
\hline & 1 & 2 & 3 & 4 & 5 & 6 & 7 & 8 & 9 & 10 & 11 & 12 & 13 & 14 & 15 & 16 & 17 & 18 & 19 & 20 & 21 \\
\hline $\begin{array}{c}\text { Effective } \\
\text { Young } \\
\text { modules, } \\
\mathrm{E}_{\mathrm{f}}(\mathrm{GPa})\end{array}$ & 893 & 909 & 930 & 893 & 880 & 893 & 909 & 930 & 893 & 893 & 870 & 880 & 893 & 909 & 875 & 893 & 893 & 905 & 880 & 893 & 909 \\
\hline $\begin{array}{c}\text { Effective } \\
\text { shear } \\
\text { modules, } \\
\mathrm{G}_{\mathrm{f}}(\mathrm{GPa})\end{array}$ & 352 & 358 & 366 & 352 & 347 & 352 & 366 & 352 & 352 & 352 & 343 & 347 & 352 & 358 & 344 & 352 & 352 & 356 & 347 & 352 & 358 \\
\hline
\end{tabular}

For studying the influence of the MWCNTs on the Young modulus of the PVA matrix, the samples were prepared according to the requirements of the nano-indentation test; using the Oliver and Parr Method (Pharr \& Oliver, 1992), the effective Young modulus for the manufactured composites was obtained. The nano-indentation tests were performed in an IBIS Authority Fischer-Cripps nano-indenter with a diamond Berkovich indenter tip. A peak load of $100 \mathrm{mN}$ was deemed, with a loading and unloading rate of $1 \mathrm{mN} / \mathrm{min}$ in order to produce quick tests and minimize the thermal creep effects; additionally, the load was held during $5 \mathrm{~s}$ to reduce the creep effects during the final unloading step. Ten nano-indentations were carried out in all composites studied.

In Fig. 5a-b, the PVA/MWCNTs effective Young moduli numerically obtained by the present methodology are compared with the ones experimentally measured by the Oliver and Pharr nano-indentation method. The experimental results indicate that the Young modulus increases with the global weight content of MWCNTs filler, $w_{M W C N T, \text { global }}$, from $w_{M W C N T, g l o b a l}=$ $0.25 \%$ to $w_{M W C N T, \text { global }}=0.50 \%$, for both the not aligned and aligned samples; however, for the composites fabricated with $w_{M W C N T, \text { global }}=1.0 \%$, experimental results evidence a decreasing of the Young modulus and this behavior is due to possible clusters formation and manufacturing errors. It is worth-noting in the experimental results that the addition of MWCNTs notoriously increases the mechanical properties with respect to the constituent PVA polymer (see Table 3) for the stretched composites; however, the properties of the unstretched composites do not considerably improve regardless the MWCNTs content. At first glance, this shows that the presence of both the nano-reinforcement and the stretching process of the matrix play a critical role in the improvement of the mechanical properties. It should be clarified that during the manufacturing process, some differences between the plastic behavior of the manufactured composites can be identified, i.e., the sample reinforced with $0.5 \mathrm{wt} \%$ presents a very good plastic deformation, and this deformation aligns the polymeric chains, thus affecting the mechanical properties of the composite, specifically the Young modulus. On the other hand, this behavior is not evidenced in the sample reinforced with $1 \mathrm{wt} . \%$ CNTs, because the larger MWCNTs content hampers more the plastic deformation during stretching, that is, the CNTs stiffen the composite more than for $0.5 \mathrm{wt} \%$. It is worth mentioning that the effect of the polymer chains alignment on the final mechanical properties is not included in the present model, which represents a possible cause of the dissimilar behavior between the experimental and numerical results (see Fig. 5a-b).

The relative differences between experimental and numerical results are shown in Table 6. As can be noticed in such table and confirmed in Fig. 5a-b, an acceptable approximation to experimental results is obtained in some cases: $0.25 \%$ nonstretched, $0.5 \%$ non-stretched, $0.25 \%$ stretched and $1 \%$ stretched. The differences between numerical and experimental results can be attributed to error sources of different nature:

- Sample preparation for composite: During the synthesis of the composite the curing rate was not controlled, i.e., little changes in the atmospheric conditions could have been affected the polymerization and curing process, leading to different heterogeneities that alter the mechanical properties of the final composite. As mentioned before, MWCNTs clusters formation and uncontrolled polymer chains alignment during the stretching process can be other relevant error sources associated to the sample preparation. 
- Dispersion and orientation characterization: as aforementioned, image analysis was used to obtain the dispersion and orientation probability functions. Random zones were selected in the nano-composite samples, and mean, $\mathrm{u}$, and standard deviation, $\sigma$, were obtained using a pre-defined grid in the TEM images. Despite not quantified in this study, image analysis carried on several kinds of errors: preparation (saturation, shadowing, etc.), integration (number, density, and location of discrete pixels) and analysis errors (segmentation and measurement calibration).

- Mechanical characterization by nano-identation: the measurements were made at high loads in order to avoid errors associated with wear of the Berkovich tip, however, the tip is very sensitive to small changes in ambient temperature and this could affect the measurement; as reasonable, this effect is more important at sudden changes in atmospheric conditions.

- Idealization errors: It is worth-noting the stochastic nature of the geometrical characteristics of MWCNTs due to their processing conditions. In the present work, 105 possible geometrical configurations were considered for MWCNTs, each of them having the same averaged weight in the numerical calculations. This is an idealization that can introduce some error, but it is necessary because a complete characterization of all MWCNTs in a sample is impractical and cumbersome. This error source is revealed in the variability of the calculated effective Young modulus of the MWCNT $\left(E_{f}\right)$, see Table 5 , and of the estimated effective elastic modulus of the nano-composite, see black, box-whisker plots of Fig. 5a-b. The stochastic nature of the geometry of MWCNTs is evidenced as well in some experimental results, like the uncertainty of the Raman spectroscopy measured elastic modulus (see Table 2) and of the nano-composite Young modulus experimentally obtained by nano-indentation (see grey box-whisker plots of Fig. 5a-b).

- Statistical error: As formerly mentioned, the Monte Carlo integration strata points are randomly generated, and thus, exactly equal results are not expected for all simulation runs of a given combination. Twenty simulation were run for each combination to achieve statistically confident results, obtaining an average standard deviation for all combinations of $3.031 \times 10^{-3} \mathrm{GPa}$, namely, three orders of magnitude lower than the nano-composites Young moduli reported in Fig. 5a$\mathrm{b}$; this shows that Monte Carlo integration brings about statistically reliable results.

Some differences are noticeable between the behavior of Young modulus with MWCNTs weight content predicted by the present statistical methodology and the one experimentally observed. Fig. 5a shows the non-aligned composite material (nonstretched) and the results evidence a minimum change of the Young modulus with the addition of the nano-reinforcement in the polymeric matrix for the experimental results; for the calculated values, the increment of Young modulus with the addition of nano-reinforcements is more notorious. These dissimilar results can be attributed to the manufacturing process; in the experimentally obtained samples, although the composites show a good dispersion degree, it is possible to find areas with nano-reinforcements agglomerations or with heterogeneities associated to the polymerization and curing process.

Similarly, Fig. $5 \mathrm{~b}$ shows the behavior of the elastic modulus with the MWCNTs weight for the nano-reinforcements aligned by mechanical stretching. The results indicate a suitable approximation of the Young modulus with the present methodology for MWCNTs weight contents of $0.25 \%$ and $1 \%$; however, an important difference between experimental and numerical result can be noticed for the weight content of $0.5 \%$, where the measured Young modulus is maximum. As previously mentioned, the high plastic deformation and consequent polymer chains alignment obtained for this particular sample could be an important cause of this difference.
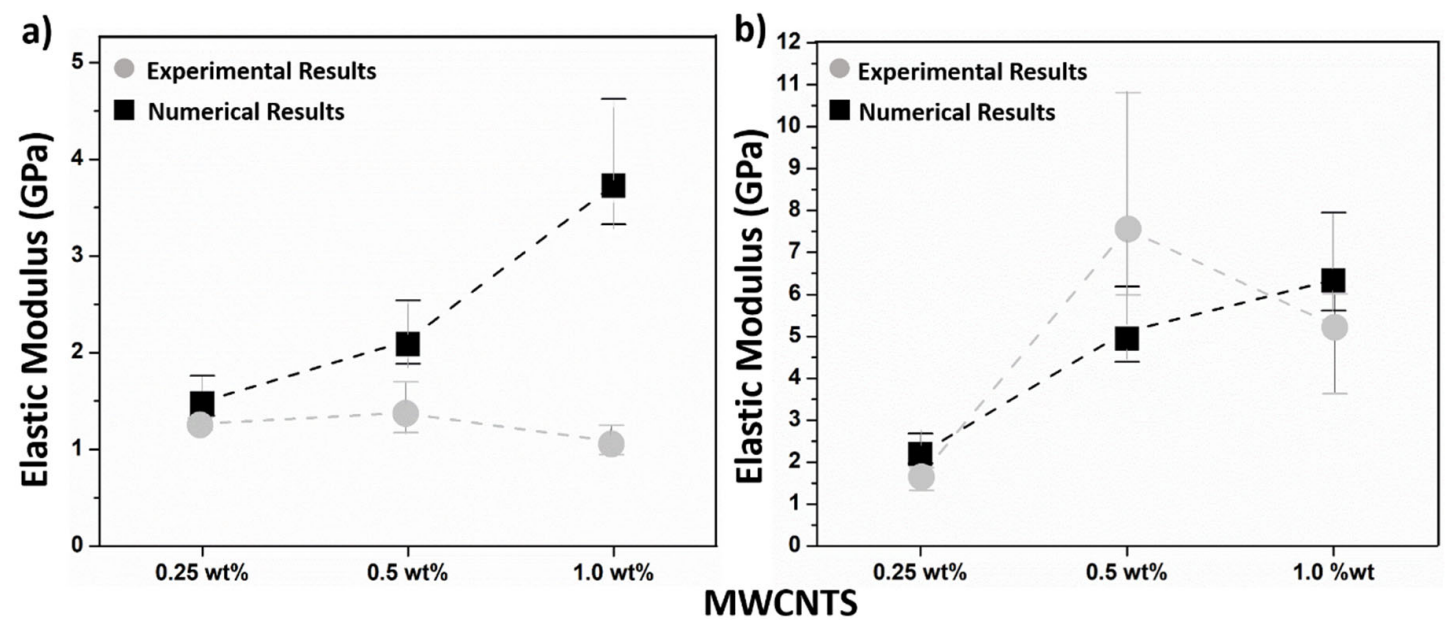

Fig. 5. Measured and calculated data for the composites studied. a) Composites with the nano-reinforcement not aligned and b) Composites with the nano-reinforcement aligned. 
Table 6. Relative differences between experimental and numerical results for the effective elastic modulus

\begin{tabular}{lcccccc}
\hline & \multicolumn{3}{c}{ Non-streched } & \multicolumn{3}{c}{ Streched } \\
\hline MWCNTs & $0.25 \%$ & $0.50 \%$ & $1.00 \%$ & $0.25 \%$ & $0.50 \%$ & $1.00 \%$ \\
Relative difference, $\mathrm{d}_{\text {rel }}$ & $26.03 \%$ & $36.40 \%$ & $276.28 \%$ & $10.60 \%$ & $37.23 \%$ & $10.42 \%$ \\
\hline
\end{tabular}

\subsection{Influence of the of the nanotube type and polymer matrix on the effective elastic modulus}

The numerical simulations for the PVA, PEEK, and UHMWPE polymeric matrices reinforced with different types of CNTs (SWCNTs, DWCNTS, and MWCNTs) are shown in Figs. 6 to 8. Statistical parameters previously obtained for the dispersion and orientation in the MWCNTs/PVA composite were used in this analysis.

The numerical results for PVA reinforced with the different types of CNTs are shown in Fig. 6a-c. As can be observed, at any given CNT weight content, the PVA reinforced with DWCNTs has a larger Young modulus than the PVA reinforced with SWCNTs and MWCNTs, for both the stretched and non-stretched cases. The lower effective Young moduli are obtained for the composite reinforced with MWCNT. This behavior is directly associated with the dimensions of the nanoreinforcement and the manufacturing processes, as previously discussed. It should be noted that the smaller dimensions of the nano-reinforcement suggest a greater response of their mechanical properties and it is due to the decrease in the crystalline and volumetric defects of the nano-reinforcements.

The percentage increment of the Young modulus of the neat polymer matrix with the addition of the nano-reinforcements is an appropriate parameter to carry out comparison with experimental results. This increment is defined as the percent ratio of the difference of elastic moduli of the reinforced and neat material to the elastic modulus of the neat matrix. Firstly, it is worth-mentioning that in the below-cited experimental works, an additional stretching process was not implemented, and differences between these results and the present numerical ones cannot be attributable to a mechanical-induced reinforcement orientation, but instead to the reinforcement dispersion and possible cluster formation not accounted in the present model. Accordingly, experimental results are compared to numerical ones for the non-stretched cases. For example, Xu et al. (2010) studied the effect of SWCNTs in PVA matrix using electrospinning technique for $0.3 \% \mathrm{wt}$., obtaining an increase in the Young modulus of $28.6 \%$. This result is lower than the increment corresponding to $0.25 \%$ wt. in Fig. $6 \mathrm{a}$, namely, $463.3 \%$, indicating a lower dispersion degree in the experimental work of Xu et al. (2010). On the other hand, Lin et al. (2016) studied the effect of MWCNTs in a PVA matrix manufactured by solution mixing and melt compounding method, achieving increments of the elastic modulus between $300 \%$ and $400 \%$ for $0.25 \%$ wt. and $0.5 \%$ wt., respectively, which is in the same order of magnitude of results obtained here for the non-aligned composites of Fig. 6c, namely, 334\% and 514\%. This implies a similar dispersion degree between this experimental work and the present one.
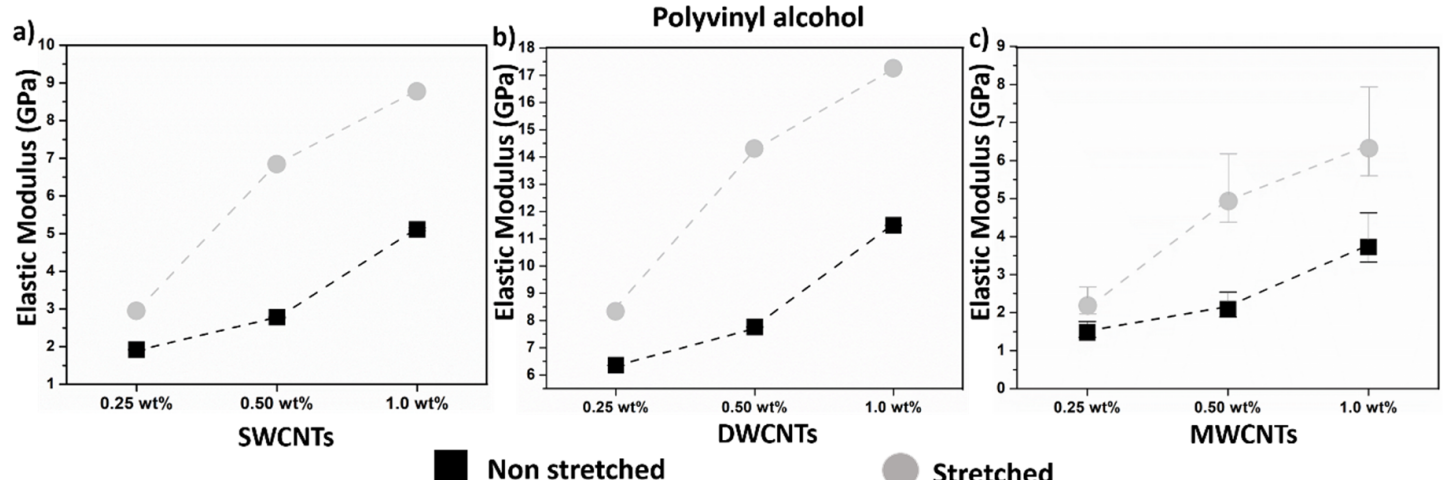

Stretched

Fig. 6. Numerical results for the PVA for both, the non-stretched and the stretched composites with different nanoreinforcement. a) SWCNTs, b) DWCNTs, and c) MWCNTs

Results for PEEK reinforced with SWCNTs, DWCNTs and MWCNTs are shown in Fig. 7. The Young modulus exhibits similar behavior in all composites compared with the PVA-matrix composites, i.e., it continuously increases with the CNT weight content, with the larger values obtained for the DWCNTs and the lower ones, for the MWCNTs; however, Young modulus is higher for PEEK-matrix than for PVA-matrix composites in all cases and this it is due to the superior mechanical properties of the PEEK matrix. Díez-Pascual et al. (2009 a,b) manufactured PEEK reinforced with SWCNTs in fractions of $0.25,0.5$ and $1.0 \%$ wt. by mold compounding technique. The authors found that the elastic modulus increases about $50 \%$ for the composite reinforced with $1.0 \%$ wt. of SWCNTs. Other authors (Shang et al., 2019) manufactured PEEK reinforced with MWCNTs using the twin-screw extruders technique, finding an increment in the Young modulus of around $25 \%$ for $1 \%$ w.t. The increments of the Young modulus reported in such works are lower than the ones obtained in the present one for 1\%w.t., namely, $158.4 \%$ for SWCNTs (Fig. 7a) and 112.8\% for MWCNTs (Fig. 7c), indicating a lower dispersion degree in the other experimental works. 


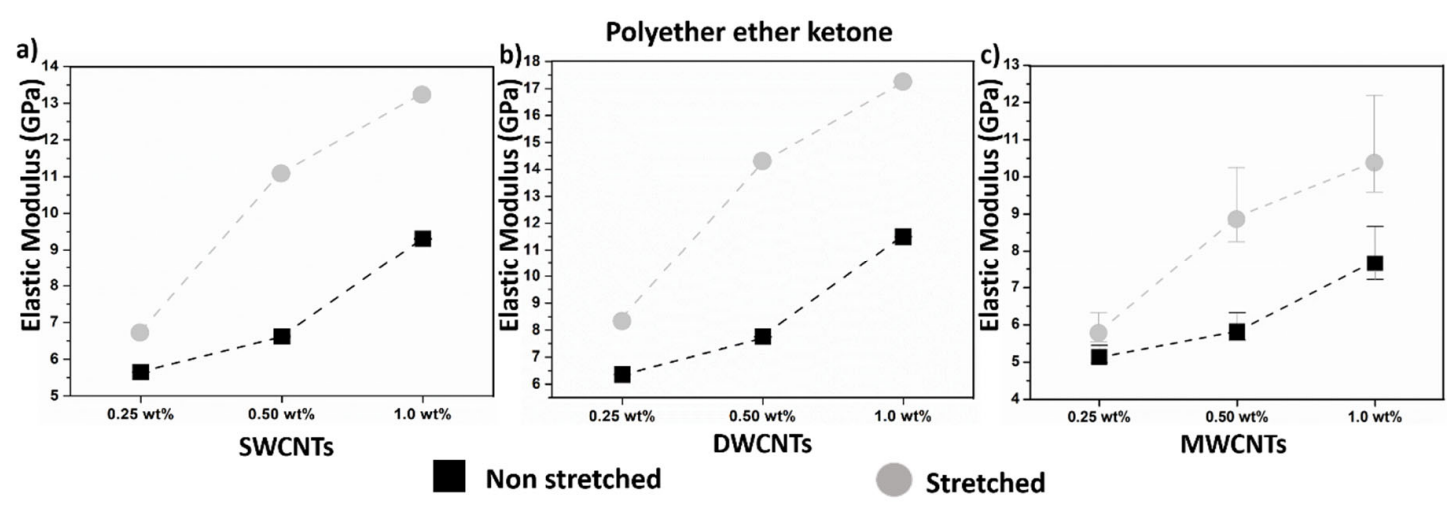

Fig. 7. Numerical results for the PEEK for both, the non-stretched and the stretched composites with different nanoreinforcement. a) SWCNTs, b) DWCNTs, and c) MWCNTs

Finally, the numerical results for nano-reinforced UHMWPE with the different types of CNTs are shown in Fig. 8. In the same way as the composites previously studied, higher increments of the Young moduli are reached for the composite reinforced with DWCNTs and lower increases are achieved for MWCNTs. Several authors have reported the change in Young modulus with the addition of MWCNTs in a UHMWPE matrix. For instance, Ruan et al. (2003) showed that the addition of 1 wt.\% MWCNTs into UHMWPE matrix increases the Young modulus around 25\%. On the other hand, Martinez-Morlanes et al. (2011) reported an increase of $38 \%$ of Young modulus. As in most of cases previously analyzed in this study, the Young modulus numerically computed shows a higher increase with respect to the other experimental studies, namely, $320.1 \%$ (see Fig. 8c).
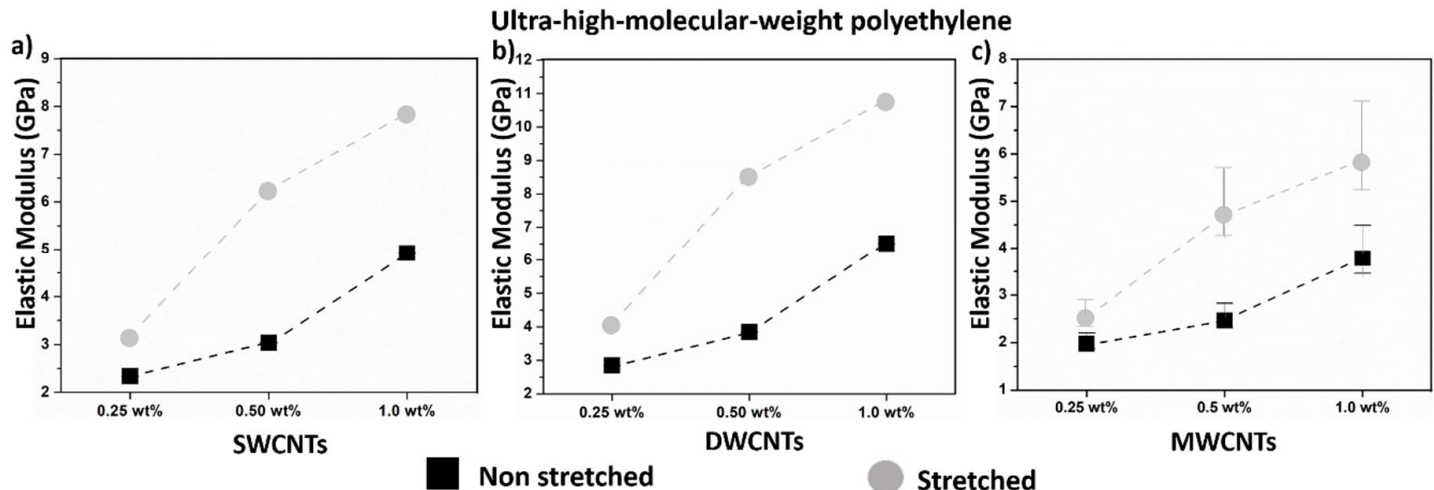

Fig. 8. Numerical Results for the UHWPE for both, the non-stretched and the stretched composites with different nanoreinforcement. a) SWCNTs, b) DWCNTs, and c) MWCNTs

\section{Conclusions}

In the present work, it was presented a Mori-Tanaka-based statistical methodology to calculate the effective Young modulus of CNTs reinforced polymer matrix composites, considering a probability distribution functions for the dispersion degree and orientation of CNTs, whose fitting parameters were obtained by TEM characterization and in-plane image analysis. The micromechanical model used to calculate the equivalent Young modulus of the MWCNTs was validated with experimental results obtained by micro-Raman spectroscopy. Despite the variability of these experiments, a relative difference of $1.76 \%$ between the experimental and analytical average Young moduli shows that the micromechanical model employed here is reliable enough. This satisfactory assessment is one of the most important aspects to achieve an acceptable prediction of the elastic properties of the MWCNTs/polymer matrix composites. The effective Young modulus of MWCNTs/PVA composites at different CNTs weight contents and alignment degree (stretched and non-stretched) were calculated by the present methodology and compared with experimental results obtained by nano-indentation test. Several similarities and differences between the numerical and experimental results were found. Firstly, the present methodology predicts an increasing monotonic behavior of the effective elastic modulus with the CNT weight content for both the stretched and nonstretched composites, whereas the experimental results show a non-monotonic behavior, with the larger modulus corresponding to the intermediate weight content, $0.5 \% \mathrm{wt}$. For the stretched cases, this is attributable to the effect of the polymeric chains alignment on the tensile mechanical behavior of the final composite; this alignment takes place during the stretching process of the sample and is less significant as the CNTs weight content increases. For the non-stretched composites, according to the experimental results, a very low improvement of the Young modulus with the addition of the MWCNTs is 
reached, which is in agreement with the numerical results for $0.25 \%$ and $0.5 \%$ wt. According to the small relative differences regarding some experimental results, the present statistical methodology is promising to predict the effective Young modulus of nano-reinforced polymer matrix composites. The proposed method is highly dependent on the accuracy of the dispersion and alignment characterization technique, which means that better numerical results can be expected by using more accurate techniques than the one employed here. The quantification of the polymeric chains alignment and the modeling of its influence on the mechanical behavior of the composite, a more accurate estimation of the distribution of the geometrical properties of the CNTs embedded in the polymeric matrix (inner and outer diameter, wall thickness, interlayer gap, etc.), the consideration of the influence of the CNTs cluster on the mechanical behavior, etc. are another particular elements that can contribute to the accuracy and applicability of the present methodology in future works. Finally, a comparative analysis on the influence of the CNTs type and polymeric matrix on the effective Young modulus of the composite was carried out. According to the numerical results, for the PVA, PEEK, and UHMWPE matrices studied here, the higher effective Young moduli are obtained with the addition of DWCNTs and the lower ones, with MWCNTs. In general, larger increments of the effective Young moduli of the polymeric matrix with the addition of CNTs in non-stretched specimens are obtained in the present model regarding previous experimental works, which can be explained by differences between dispersion degrees of experiments and the ones considered in the numerical model using a dispersion probability function, where some associated phenomena, as the reduction of mechanical performance by clusters formation, are not still considered.

\section{Acknowledgements}

The authors would like to thank Institución Universitaria Pascual Bravo for the financial support to the research "Diseño y fabricación de una pico central eléctrica con turbina tipo Pelton por medio de fundición y mecanizado por control numérico computarizado (CNC)" and "Diseño de estrategias de inyección asistido por simulación computacional para reducir la formación de vacíos y mejorar el desempeño mecánico de piezas fabricadas por procesos de moldeo líquido".

\section{References}

Ahmed, S., \& Jones, F. (1990). A review of particulate reinforcement theories for polymer composites. Journal of Materials Science, 25(12), 4933-4942.

Aragh, B. S., Barati, A. N., \& Hedayati, H. (2012). Eshelby-Mori-Tanaka approach for vibrational behavior of continuously graded carbon nanotube-reinforced cylindrical panels. Composites Part B: Engineering, 43(4), 1943-1954.

Armbrister, C. E., Okoli, O. I., \& Shanbhag, S. (2015). Micromechanics predictions for two-phased nanocomposites and threephased multiscale composites: A review. Journal of Reinforced Plastics and Composites, 34(8), 605-623.

Barati, M. R., \& Zenkour, A. M. (2019). Vibration analysis of functionally graded graphene platelet reinforced cylindrical shells with different porosity distributions. Mechanics of Advanced Materials and Structures, 26(18), 1580-1588.

Brodnyan, J. G. (1959). The concentration dependence of the Newtonian viscosity of prolate ellipsoids. Transactions of the Society of Rheology, 3(1), 61-68.

Coleman, J. N., Khan, U., Blau, W. J., \& Gun'ko, Y. K. (2006). Small but strong: a review of the mechanical properties of carbon nanotube-polymer composites. Carbon, 44(9), 1624-1652.

Cox, H. (1952). The elasticity and strength of paper and other fibrous materials. British Journal of Applied Physics, 3(3), 72.

Chen, Z., Wu, Y., Yang, Y., Li, J., Xie, B., Li, X., . . . Zhou, Q. (2018). Multilayered carbon nanotube yarn based optoacoustic transducer with high energy conversion efficiency for ultrasound application. Nano Energy, 46, 314-321.

Choi, H., Shin, J., Min, B., Park, J., \& Bae, D. (2009). Reinforcing effects of carbon nanotubes in structural aluminum matrix nanocomposites. Journal of Materials Research, 24(8), 2610-2616.

Christensen, R., \& Waals, F. (1972). Effective stiffness of randomly oriented fibre composites. Journal of Composite Materials, $6(4), 518-532$.

De Villoria, R. G., \& Miravete, A. (2007). Mechanical model to evaluate the effect of the dispersion in nanocomposites. Acta Materialia, 55(9), 3025-3031.

Dervishi, E., Li, Z., Xu, Y., Saini, V., Biris, A. R., Lupu, D., \& Biris, A. S. (2009). Carbon nanotubes: synthesis, properties, and applications. Particulate Science and Technology, 27(2), 107-125.

Desai, A., \& Haque, M. (2005). Mechanics of the interface for carbon nanotube-polymer composites. Thin-walled structures, 43(11), 1787-1803.

Diez-Pascual, A., Naffakh, M., Gómez, M., Marco, C., Ellis, G., Gonzalez-Dominguez, J., . . Simard, B. (2009a). The influence of a compatibilizer on the thermal and dynamic mechanical properties of PEEK/carbon nanotube composites. Nanotechnology, 20(31), 315707.

Díez-Pascual, A. M., Naffakh, M., Gómez, M. A., Marco, C., Ellis, G., Martínez, M. T., .. . Simard, B. (2009b). Development and characterization of PEEK/carbon nanotube composites. Carbon, 47(13), 3079-3090.

Dunn, M., \& Ledbetter, H. (1995). Elastic moduli of composites reinforced by multiphase particles.

Ebrahimi, F., \& Dabbagh, A. (2019). A comprehensive review on modeling of nanocomposite materials and structures. Journal of Computational Applied Mechanics, 50(1), 197-209.

Enqvist, E., Ramanenka, D., Marques, P. A., Gracio, J., \& Emami, N. (2016). The effect of ball milling time and rotational speed on ultra high molecular weight polyethylene reinforced with multiwalled carbon nanotubes. Polymer Composites, 37(4), $1128-1136$.

Feng, W., Bai, X., Lian, Y., Liang, J., Wang, X., \& Yoshino, K. (2003). Well-aligned polyaniline/carbon-nanotube composite films grown by in-situ aniline polymerization. Carbon, 41(8), 1551-1557.

Gao, J., He, Y., \& Gong, X. (2018). Effect of electric field induced alignment and dispersion of functionalized carbon nanotubes on properties of natural rubber. Results in Physics, 9, 493-499. 
Gao, X.-L., \& Li, K. (2005). A shear-lag model for carbon nanotube-reinforced polymer composites. International Journal of Solids and Structures, 42(5-6), 1649-1667.

García-Macías, E., Rodríguez-Tembleque, L., Castro-Triguero, R., \& Sáez, A. (2017). Eshelby-Mori-Tanaka approach for postbuckling analysis of axially compressed functionally graded CNT/polymer composite cylindrical panels. Composites Part B: Engineering, 128, 208-224.

Ghorbanpour Arani, A., Baba Akbar Zarei, H., \& Haghparast, E. (2016). Application of Halpin-Tsai Method in Modelling and Sizedependent Vibration Analysis of CNTs/fiber/polymer Composite Microplates. Journal of Computational Applied Mechanics, 47(1), 45-52.

Guo, J., Briggs, N., Crossley, S., \& Grady, B. P. (2018). A new finding for carbon nanotubes in polymer blends: Reduction of nanotube breakage during melt mixing. Journal of Thermoplastic Composite Materials, 31(1), 110-118.

Halpin, J. (1969). Stiffness and expansion estimates for oriented short fiber composites. Journal of Composite Materials, 3(4), 732734.

Halpin, J. C., \& Kardos, J. (1976). The Halpin-Tsai equations: a review. Polymer Engineering and Science, 16(5), $344-352$.

Hashin, Z. (1966). Viscoelastic fiber reinforced materials. AIAA journal, 4(8), 1411-1417.

Hashin, Z. (1983). Analysis of composite materials - a survey. Journal of Applied Mechanics, 50(3), 481-505.

Hashin, Z., \& Rosen, B. W. (1964). The elastic moduli of fiber-reinforced materials.

Hashin, Z., \& Shtrikman, S. (1963). A variational approach to the theory of the elastic behaviour of multiphase materials. Journal of the Mechanics and Physics of Solids, 11(2), 127-140.

Hill, R. (1965). Theory of mechanical properties of fibre-strengthened materials-III. Self-consistent model. Journal of the Mechanics and Physics of Solids, 13(4), 189-198.

Hone, J., Llaguno, M., Biercuk, M., Johnson, A., Batlogg, B., Benes, Z., \& Fischer, J. (2002). Thermal properties of carbon nanotubes and nanotube-based materials. Applied physics A, 74(3), 339-343.

Hu, H., Onyebueke, L., \& Abatan, A. (2010). Characterizing and modeling mechanical properties of nanocomposites-review and evaluation. Journal of Minerals and Materials Characterization and Engineering, 9(04), 275.

Hu, Z., Arefin, M. R. H., Yan, X., \& Fan, Q. H. (2014). Mechanical property characterization of carbon nanotube modified polymeric nanocomposites by computer modeling. Composites Part B: Engineering, 56, 100-108.

Huang, Z.-M., Zhang, Y.-Z., Kotaki, M., \& Ramakrishna, S. (2003). A review on polymer nanofibers by electrospinning and their applications in nanocomposites. Composites Science and Technology, 63(15), 2223-2253.

Hui, C., \& Shia, D. (1998). Simple formulae for the effective moduli of unidirectional aligned composites. Polymer Engineering \& Science, 38(5), 774-782.

Huong, P. V., Cavagnat, R., Ajayan, P., \& Stephan, O. (1995). Temperature-dependent vibrational spectra of carbon nanotubes. Physical review B, 51(15), 10048.

Hyer, M. W., \& White, S. R. (2009). Stress analysis of fiber-reinforced composite materials: DEStech Publications, Inc.

Iijima, S. (1991). Helical microtubules of graphitic carbon. Nature, 354(6348), 56.

Isaza M, C. A., Herrera Ramírez, J., Ledezma Sillas, J., \& Meza, J. (2018). Dispersion and alignment quantification of carbon nanotubes in a polyvinyl alcohol matrix. Journal of Composite Materials, 52(12), 1617-1626.

Kim, M., Okoli, O., Jack, D., Park, Y.-B., \& Liang, Z. (2011). Characterisation and modelling of CNT-epoxy and CNT-fibre-epoxy composites. Plastics, Rubber and Composites, 40(10), 481-490.

Kumar, J. P., \& Srinivas, J. (2018). Three phase composite cylinder assemblage model for analyzing the elastic behavior of MWCNT-reinforced polymers. Computers Materials and Continua, 54(1), 1-20.

Kundalwal, S. I. (2018). Review on micromechanics of nano-and micro-fiber reinforced composites. Polymer Composites, 39(12), 4243-4274.

Lin, J. H., Lin, Z. I., Pan, Y. J., Hsieh, C. T., Huang, C. L., \& Lou, C. W. (2016). Thermoplastic polyvinyl alcohol/multiwalled carbon nanotube composites: preparation, mechanical properties, thermal properties, and electromagnetic shielding effectiveness. Journal of Applied Polymer Science, 133(21).

Lourie, O., \& Wagner, H. (1998). Evaluation of Young's modulus of carbon nanotubes by micro-Raman spectroscopy. Journal of Materials Research, 13(9), 2418-2422.

Luo, Z., \& Koo, J. (2007). Quantifying the dispersion of mixture microstructures. Journal of Microscopy, 225(2), 118-125.

Mallick, P. K. (2007). Fiber-reinforced composites: materials, manufacturing, and design: CRC press.

Martínez-Morlanes, M., Castell, P., Martínez-Nogués, V., Martinez, M., Alonso, P. J., \& Puértolas, J. (2011). Effects of gammairradiation on UHMWPE/MWNT nanocomposites. Composites Science and Technology, 71(3), 282-288.

Mooney, M. (1951). The viscosity of a concentrated suspension of spherical particles. Journal of Colloid Science, 6(2), 162-170.

Mori, T., \& Tanaka, K. (1973). Average stress in matrix and average elastic energy of materials with misfitting inclusions. Acta Metallurgica, 21(5), 571-574.

Noor, N., Razak, J., Ismail, S., Mohamad, N., Tee, L., Munawar, R., \& Junid, R. (2018). Review on Carbon Nanotube based Polymer Composites and Its Applications. Journal of Advanced Manufacturing Technology (JAMT), 12(1), 311-326.

Odegard, G. M., Gates, T., Wise, K., Park, C., \& Siochi, E. (2003). Constitutive modeling of nanotube-reinforced polymer composites. Composites Science and Technology, 63(11), 1671-1687.

Pharr, G., \& Oliver, W. (1992). Measurement of thin film mechanical properties using nanoindentation. Mrs Bulletin, 17(7), 28-33.

Qiu, Y., \& Weng, G. (1990). On the application of Mori-Tanaka's theory involving transversely isotropic spheroidal inclusions. International Journal of Engineering Science, 28(11), 1121-1137.

Rafiee, M. A., Rafiee, J., Wang, Z., Song, H., Yu, Z.-Z., \& Koratkar, N. (2009). Enhanced mechanical properties of nanocomposites at low graphene content. ACS Nano, 3(12), 3884-3890.

Rathi, A., \& Kundalwal, S. I. (2020). Mechanical and fracture behavior of MWCNT/ZrO2/epoxy nanocomposite systems: Experimental and numerical study. Polymer Composites. 
Reddy, J. N. (2003). Mechanics of laminated composite plates and shells: theory and analysis: CRC press.

Reuss, A. (1929). Berechnung der Flieggrenze yon Mischkristallen auf Grund der Plastizithtsbedingung fiir Einkristalle. Z. Angew. Math. Mech, 9.

Ruan, S., Gao, P., Yang, X. G., \& Yu, T. (2003). Toughening high performance ultrahigh molecular weight polyethylene using multiwalled carbon nanotubes. Polymer, 44(19), 5643-5654.

Sadeghpour, E., Guo, Y., Chua, D., \& Shim, V. P. (2020). A Modified Mori-Tanaka Approach Incorporating Filler-Matrix Interface Failure to Model Graphene/Polymer Nanocomposites. International Journal of Mechanical Sciences, 105699.

Schaufele, a., \& Shimanouchi, T. (1967). Longitudinal acoustical vibrations of finite polymethylene chains. The Journal of Chemical Physics, 47(9), 3605-3610.

Seidel, G. D., \& Lagoudas, D. C. (2006). Micromechanical analysis of the effective elastic properties of carbon nanotube reinforced composites. Mechanics of Materials, 38(8-10), 884-907.

Shang, Y., Wu, X., Liu, Y., Jiang, Z., Wang, Z., Jiang, Z., \& Zhang, H. (2019). Preparation of PEEK/MWCNTs composites with excellent mechanical and tribological properties. High Performance Polymers, 31(1), 43-50.

Shao, L., Luo, R., Bai, S., \& Wang, J. (2009). Prediction of effective moduli of carbon nanotube-reinforced composites with waviness and debonding. Composite Structures, 87(3), 274-281.

Sharma, K., \& Shukla, M. (2014). Three-phase carbon fiber amine functionalized carbon nanotubes epoxy composite: processing, characterisation, and multiscale modeling. Journal of Nanomaterials, 2014.

Sheng, N., Boyce, M. C., Parks, D. M., Rutledge, G., Abes, J., \& Cohen, R. (2004). Multiscale micromechanical modeling of polymer/clay nanocomposites and the effective clay particle. Polymer, 45(2), 487-506.

Shi, Y.-D., Yu, H.-O., Li, J., Tan, Y.-J., Chen, Y.-F., Wang, M., . . Guo, S. (2018). Low magnetic field-induced alignment of nickel particles in segregated poly (l-lactide)/poly ( $\varepsilon$-caprolactone)/multi-walled carbon nanotube nanocomposites: Towards remarkable and tunable conductive anisotropy. Chemical Engineering Journal, 347, 472-482.

Shingare, K., Gupta, M., \& Kundalwal, S. (2020). Evaluation of effective properties for smart graphene reinforced nanocomposite materials. Materials Today: Proceedings, 23, 523-527.

Shingare, K., \& Kundalwal, S. (2019). Static and dynamic response of graphene nanocomposite plates with flexoelectric effect. Mechanics of Materials, 134, 69-84.

Smith, W. A., \& Auld, B. A. (1991). Modeling 1-3 composite piezoelectrics: thickness-mode oscillations. IEEE Transactions on Ultrasonics, Ferroelectrics, and Frequency Control, 38(1), 40-47.

Stecenko, T., \& Piggott, M. (1997). Fiber waviness and other mesostructures in filament wound materials. Journal of Reinforced Plastics and Composites, 16(18), 1659-1674.

Tandon, G. P., \& Weng, G. J. (1984). The effect of aspect ratio of inclusions on the elastic properties of unidirectionally aligned composites. Polymer Composites, 5(4), 327-333.

Taya, M., \& Chou, T.-W. (1981). On two kinds of ellipsoidal inhomogeneities in an infinite elastic body: an application to a hybrid composite. International Journal of Solids and Structures, 17(6), 553-563.

Tucker III, C. L., \& Liang, E. (1999). Stiffness predictions for unidirectional short-fiber composites: review and evaluation. Composites Science and Technology, 59(5), 655-671.

Vázquez-Moreno, J. M., Sánchez-Hidalgo, R., Sanz-Horcajo, E., Viña, J., Verdejo, R., \& López-Manchado, M. A. (2019). Preparation and Mechanical Properties of Graphene/Carbon Fiber-Reinforced Hierarchical Polymer Composites. Journal of Composites Science, 3(1), 30.

Verma, P., Saini, P., Malik, R. S., \& Choudhary, V. (2015). Excellent electromagnetic interference shielding and mechanical properties of high loading carbon-nanotubes/polymer composites designed using melt recirculation equipped twin-screw extruder. Carbon, 89, 308-317.

Wagner, H. D. (1996). Thermal residual stress in composites with anisotropic interphases. Physical Review B, $53(9), 5055$.

Wang, J., \& Pyrz, R. (2004). Prediction of the overall moduli of layered silicate-reinforced nanocomposites-part I: basic theory and formulas. Composites Science and Technology, 64(7-8), 925-934.

Weng, G. (1984). Some elastic properties of reinforced solids, with special reference to isotropic ones containing spherical inclusions. International Journal of Engineering Science, 22(7), 845-856.

Wu, Y., Zhang, X., Leung, A., \& Zhong, W. (2006). An energy-equivalent model on studying the mechanical properties of singlewalled carbon nanotubes. Thin-walled Structures, 44(6), 667-676.

Xie, S., Li, W., Pan, Z., Chang, B., \& Sun, L. (2000). Mechanical and physical properties on carbon nanotube. Journal of Physics and Chemistry of Solids, 61(7), 1153-1158.

Xu, X., Uddin, A. J., Aoki, K., Gotoh, Y., Saito, T., \& Yumura, M. (2010). Fabrication of high strength PVA/SWCNT composite fibers by gel spinning. Carbon, 48(7), 1977-1984.

Yeh, M.-K., Tai, N.-H., \& Liu, J.-H. (2006). Mechanical behavior of phenolic-based composites reinforced with multi-walled carbon nanotubes. Carbon, 44(1), 1-9.

Zhang, Y., \& Wang, X. (2005). Thermal effects on interfacial stress transfer characteristics of carbon nanotubes/polymer composites. International Journal of Solids and Structures, 42(20), 5399-5412.

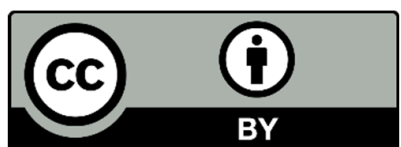

(C) 2022 by the authors; licensee Growing Science, Canada. This is an open access article distributed under the terms and conditions of the Creative Commons Attribution (CC-BY) license (http://creativecommons.org/licenses/by/4.0/). 